\title{
Caracterización sedimentológica de un Sistema Fluvial Distributivo de clima árido: arroyo Papagayos, en el piedemonte oriental de las Sierras La Huerta-Imanas, San Juan, Argentina
}

\author{
Paula Santi Malnis ${ }^{1,2}$, Carina E. Colombi ${ }^{1,2}$, Natalia Rodríguez Posatini ${ }^{2}$, \\ Luis M. Rothis ${ }^{1,3}$, Carlos O. Limarino ${ }^{4}$
}

\begin{abstract}
I Consejo Nacional de Investigaciones Científicas y Tecnológicas (CONICET), Centro de Investigaciones de la Geósfera y la Biósfera (CIGEOBIO), Av. Ignacio de la Roza 590 (O), Complejo Universitario “Islas Malvinas”, Rivadavia, San Juan J5402DCS, Argentina. pmalnis@unsj.edu.ar; ccolombi@unsj.edu.ar;marothis@gmail.com

2 Instituto y Museo de Ciencias Naturales, Facultad de Ciencias Exactas Físicas y Naturales, Universidad Nacional de San Juan, Av. España 400 (N), Ciudad de San Juan, San Juan J5400DNQ, Argentina. natygem@hotmail.com

3 Gabinete de Geomorfología y Neotectónica, Instituto de Investigaciones Geológicas (INGEO), Facultad de Ciencias Exactas Físicas y Naturales, Universidad Nacional de San Juan, Av. Ignacio de la Roza 590 (O), Complejo Universitario “Islas Malvinas”, Rivadavia, San Juan J5402DCS, Argentina.

${ }^{4}$ Instituto de Geociencias Básicas, Aplicadas y Ambientales de Buenos Aires (IGEBA), Universidad de Buenos Aires, Intendente Güiraldes 2160, Pabellón II, Piso 1, Ciudad Universitaria, Buenos Aires 1428, Argentina.
\end{abstract}

limar@gl.fcen.uba.ar

RESUMEN. En los últimos 10 años nuevos modelos sedimentarios para cuencas intermontanas ponen en discusión la dinámica depositacional clásicamente considerada (dominio de abanicos aluviales y grandes sistemas fluviales) para estas cuencas, tal es el caso de los Sistemas Fluviales Distributivos (SFD). Con el fin de comprender los procesos sedimentarios formadores de los SFD, en este trabajo se discuten los distintos subambientes sedimentarios del arroyo Papagayos y su terminación como un SFD. Para ello se analizan los subambientes sedimentarios del arroyo Papagayos teniendo en cuenta los diferentes elementos arquitecturales que lo conforman, como respuesta a las características morfométricas de su cuenca de drenaje, la interacción del clima en las cabeceras y en el valle, y las características geomorfológicas del piedemonte y del valle en el que se inserta, ubicado en el antepaís fracturado andino. El análisis sedimentológico y geomorfológico realizado en el arroyo Papagayos permite diferenciar cuatro zonas a lo largo de su recorrido: una proximal en donde se desarrolla un sistema fluvial entrelazado de carga gravosa y arenosa; una media caracterizada por un sistema fluvial anastomosado-anabranching arenoso y gravoso; una distal en donde se desarrolla un sistema fluvial distal efímero de carga arenosa de alta sinuosidad, con importante interacción eólica; y una de transición que correspondería a la faja litoral de la salina de Mascasín. Por otra parte, se observó que entre los procesos sedimentarios reconocidos en estos ambientes los flujos densos, especialmente los flujos cohesivos de barro, constituyen uno de los mecanismos más importantes de depositación en la llanura de inundación. Los procesos sedimentarios reconocidos a lo largo del arroyo Papagayos, y descritos en este trabajo, permiten no solo caracterizar mejor a los SFD de clima árido sino también facilitar su reconocimiento en ambientes antiguos.

Palabras clave: SFD, Cuencas intermontanas, Clima estacional, Sierras Pampeanas Occidentales. 


\begin{abstract}
Sedimentological characterization of a Distributive Fluvial System of arid climates: arroyo Papagayos, eastern piedmont of La Huerta-Las Imanas Ranges, San Juan, Argentina. Recent studies proposed that distributive fluvial systems (DFS) occupy a great proportion in modern continental sedimentary basins, challenging classical sedimentary models proposed for similar ancient basin. Because of this, arises the importance of studying modern DFS with the aim of obtaining facial models to apply them in ancient deposits. In this paper, we analyze and discuss the sedimentary environments included in the modern deposits of the Arroyo Papagayos, Western Pampean Ranges, San Juan province, interpreted as a Distributive Fluvial System (DFS). We perform the study of the Papagayos creek by describing different architectural elements, which characterize the sub-environments organized in four zones from the mountain front to the distal playa lake. A low sinuosity gravelly-sandy bed braided fluvial system, characterizes the proximal zone. A medial to high sinuosity sandy-gravelly anastomosed-anabranching fluvial system describes the medial zone, where floodplain aggradation is domain by crevasse splays accretion. At this point, $10 \mathrm{~km}$ far from the mountain front, the deposits starts to develop a cone shaped morphology. A higher sinuosity flashy ephemeral meandering sandymuddy fluvial system with eolian interaction defines the distal zone, where the main channel of the system disappears by low gradient of the topography and infiltration depositing muddy terminal splays. Finally, eolian dune and wet interdune deposits characterizes the fourth zone, interpreted as a transitional area between the DFS and the saline playa lake. A particular feature observed along the DFS system is that mudflows are the main sedimentary process in the floodplain, probably as the result of the combination of the seasonal arid climate and the Arroyo Papagayos drainage basin morphometry and the low gradient of the topography. The sedimentary process and environments recognized along the Arroyo Papagayos will allow a better understanding of arid DFS depositional dynamics as well as, to identify them in the geological record. Lastly, high aggrading conditions for DFS development will response to climate interaction between upland catchment area (semiarid) and valley (arid), drainage basin morphometry, smooth piedmont gradient and high tectonic subsidence of the basin, located in the Andean broken foreland.
\end{abstract}

Keywords: DFS, Intermontane basin, Seasonal climate, Western Pampean Ranges.

\section{Introducción}

En los valles intermontanos se reconocen diferentes ambientes sedimentarios que se organizan en dos grandes sistemas de drenaje. Por un lado, los sistemas de drenaje transversal, que se ubican en los piedemontes y se encargan de organizar la llegada de agua y sedimentos desde las cabeceras o umbrales al valle, y por otro lado, los sistemas de drenaje axial, que reciben los materiales de los drenajes transversales llevándolos al nivel de base. Los primeros están representados por diferentes ambientes sedimentarios de piedemonte como taludes, abanicos coluviales, piedemonte dominado por flujos canalizados y abanicos aluviales, como los observados en el bolsón de Hualilan (e.g., Suriano y Limarino, 2009). Los segundos, discurren paralelos a los márgenes del valle y es común que estén representados por extensos ríos, asociados a lagos, barreales o salinas que se desarrollan a lo largo de su recorrido, tal como puede verse en el río Bermejo (La Rioja, San Juan, Mendoza), las salinas de Mascasín y las Salinas Grandes (La Rioja, San Juan, San Luis).

Sin embargo, una parte importante de los sedimentos vinculados a áreas orogénicas (como por ejemplo la Cordillera de los Andes) son acumulados por un sistema poco estudiado hasta la última década, que generalmente se desarrolla en forma transversal al valle intermontano. Este sistema resulta intermedio entre sistemas fluviales y abanicos aluviales, difiere de los primeros en el diseño distributario de la red de canales y de los segundos en que se ubican más allá de los frentes montañosos y están dominados por sedimentos de grano fino. Para estas acumulaciones fueron propuestos distintos nombres, por lo que en ocasiones se los reconoce como abanicos terminales por su ubicación lejana al frente montañoso, abanicos fluviales por la dinámica de los procesos sedimentarios dominantes y otras veces mega-abanicos por la magnitud que pueden llegar a alcanzar (Nichols y Fisher, 2007; Hartley et al., 2010; Colombo, 2010). Otros nombres utilizados, tales como sistemas distributarios fluviales o sistemas fluviales distributivos (SFD; Fluvial Distributary System, Nichols y Fisher, 2007; Distributive Fluvial System, Hartley et al., 2010) corresponden a cuerpos sedimentarios de mayor envergadura y alcanzan hasta miles de kilómetros cuadrados de extensión. Es interesante señalar que según algunos autores los sistemas fluviales distributivos representan hasta el $80 \%$ de los sedimentos que se acumulan en cuencas continentales (Weissmann et al., 2010). Este tipo de ambiente ha sido caracterizado como sistemas fluviales cuya descarga decrece aguas abajo, al 
separase en cursos radiales que distribuyen el agua y generan un abanico lejos del frente montañoso, finalizando el sistema en lóbulos terminales (Nichols y Fisher, 2007). Otra definición, los describe como sistemas de canales radiales y depósitos asociados que se dispersan a partir de un ápice, donde un río emerge del confinamiento (cañadón) e ingresa en una cuenca sedimentaria (Weissmann et al., 2010). Sin embargo, cabe aclarar que a diferencia de los abanicos aluviales, en estos ambientes la morfología de "abanico" se produce lejos del frente montañoso. Sea cual sea la definición, estos sistemas se caracterizan por estar alejados del frente montañoso, desarrollarse en piedemontes de baja pendiente, estar dominados por procesos sedimentarios fluidos, presentar un patrón distributivo en planta, decrecer la profundidad, ancho e interconectividad de los canales aguas abajo, y tener una topografía convexa y lobulada (Friend, 1978; Nichols y Fisher, 2007; Hartley et al., 2010).

Pese a que estos ambientes se convirtieron en objeto de investigación debido al alto porcentaje observado en el ambiente actual, los mismos han sido poco reconocidos en el registro sedimentario (Nichols y Fisher, 2007; Weissmann et al., 2010; Hartley et al., 2010; Davidson et al., 2013; Colombi et al., 2015a). Una posibilidad es que las condiciones climáticas y geológicas pasadas no hayan favorecido los procesos sedimentarios encargados de su formación. Sin embargo, y siguiendo el principio del uniformismo, es más probable que las condiciones depositacionales hayan sido similares y que su ausencia en la bibliografía se deba a una falta de reconocimiento de los mismos en el registro, confundiéndolos con sistemas aluviales o fluviales clásicos. Esto refleja la falta de criterios sedimentológicos claros que permitan su incuestionable reconocimiento y diferenciación.

En esta contribución se pretende aportar elementos diagnósticos que permitan el reconocimiento de estos sistemas en el registro geológico, utilizando para ello el ejemplo actual del SFD del arroyo Papagayos, desarrollado bajo un clima árido (Santi Malnis et al., 2016). El arroyo Papagayos tiene sus cabeceras en la sierras de La Huerta-Las Imanas, desaguando en el piedemonte oriental de la misma, hasta alcanzar las salinas de Mascasín, al Este de la provincia de San Juan. Este arroyo pierde el confinamiento al salir de la sierra y desarrolla un sistema fluvial entrelazado por más de $10 \mathrm{~km}$ que cambia a un sistema fluvial anastomosado y culmina en cursos fluviales meandriformes radiales que desembocan en lóbulos terminales en la faja costera de las salinas de Mascasín (Fig. 1).

Para su caracterización se realizó un estudio geomorfológico y sedimentológico de detalle, con el fin de describir los diferentes procesos de cada subambiente a lo largo y ancho de todo el sistema.

\section{Marco Geológico}

Al Este de la ciudad de San Juan y en el límite con la provincia de La Rioja, se desarrolla un valle intermontano denominado Depresión del Gran Bajo Oriental, emplazado en las Sierras Pampeanas Occidentales en el antepaís fracturado (Criado Roque et al., 1981; Jordan et al., 1983; Suvires, 1996). Este valle está circunscrito por las sierras de La Huerta, Las Imanas, y Lomas de Leyes al Oeste, y las sierras de Chepes, Ulapes y Las Minas por el Este (Fig. 1). Las sierras de La Huerta-Imanas están formadas por rocas de basamento cristalino representado por el Complejo Valle Fértil, y rocas sedimentarias triásicas del Grupo Marayes y cretácicas del Grupo El Gigante (Bossi, 1976; Vujovich et al., 2007). Su piedemonte oriental presenta conos aluviales cuaternarios, y en las inmediaciones de las salinas se presentan acumulaciones eólicas de los Médanos Negros y dunas longitudinales y transversales (Suvires, 1986; Vujovich et al., 2007; Tripaldi y Forman, 2007). Los Médanos Negros y las dunas transversales al borde de la salina han sido datadas por Luminiscencia Ópticamente Estimulada (OSL) en $2.540 \pm 240$ años y entre $900 \pm 70$ y $400 \pm 65$ años respectivamente (Tripaldi y Forman, 2007). Los depósitos sedimentarios del arroyo Papagayos en parte cubren y se interdigitan con estos depósitos eólicos.

El marco tectónico de la cuenca de Las Salinas fue interpretado a través de datos de subsuelo como una serie de anticlinales asimétricos de rumbo nornoreste, cuyos flancos occidentales están truncados por fallas inversas paralelas al eje del anticlinal (Criado Roque et al., 1981; Azeglio et al., 2008; Azeglio et al., 2010). La cuenca de Las Salinas tendría un origen extensional, cambiando hacia fines del Cenozoico a compresional por la orogenia Andina, que origina un fallamiento inverso que eleva rocas mesozoicas y neógenas a nivel de superficie (Criado Roque et al., 1981). La subsidencia de la cuenca de Las Salinas, de acuerdo a diagramas de tiempoprofundidad, habría aumentado durante el MiocenoPlioceno a causa de la adición de una componente 


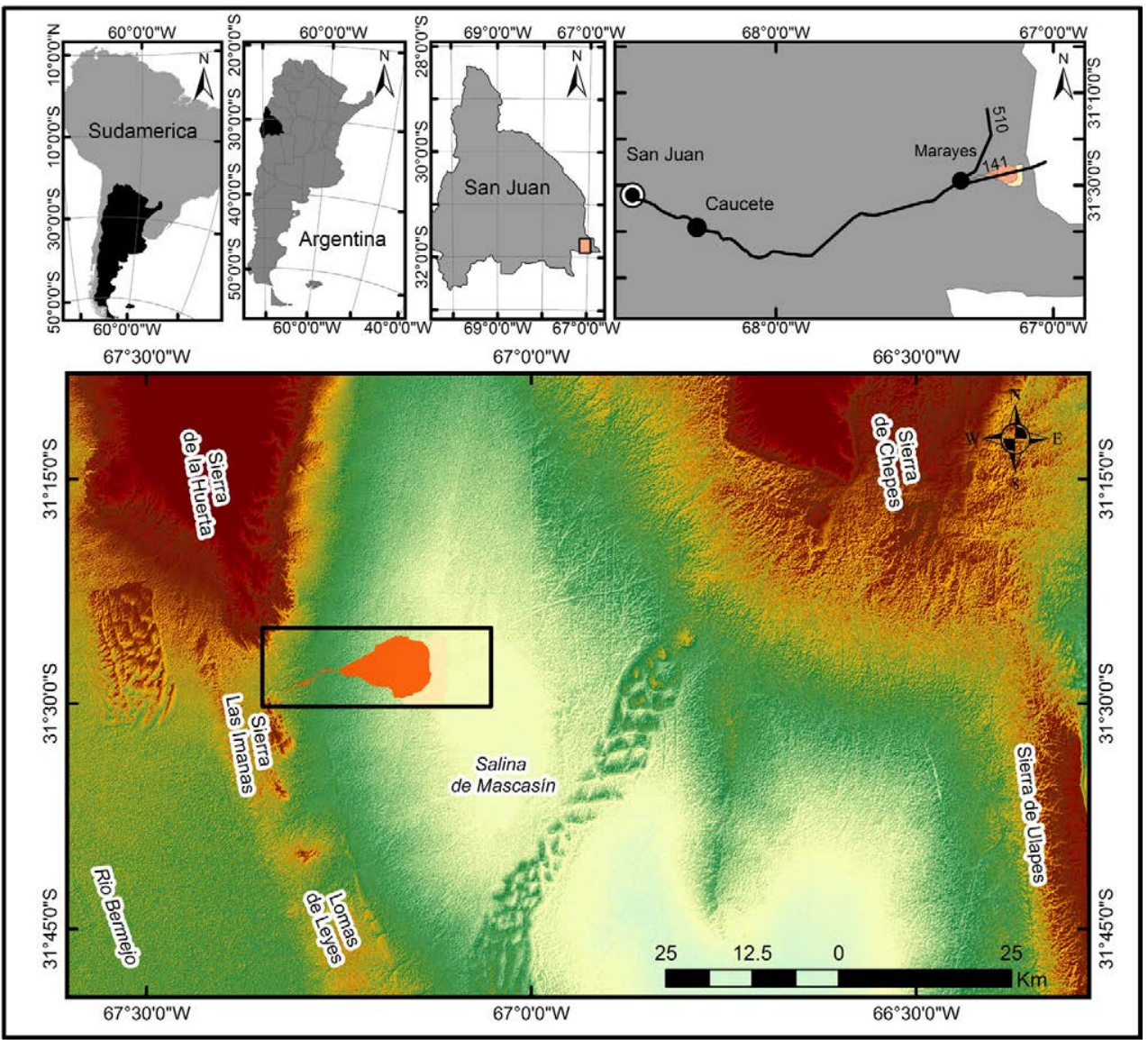

FIG. 1. Ubicación de la zona de estudio a nivel regional y local. En la imagen se destaca en colores rosados y naranjas los depósitos del SFD del arroyo Papagayos, incluidos en el rectángulo.

tectónica a la subsidencia por carga litostática. Estas condiciones se mantienen hasta el presente, con un ligera disminución de la velocidad de subsidencia en los depósitos cuaternarios (de 0,328 a 0,10 mm/año; Azeglio et al., 2008; Azeglio et al., 2010).

\section{Clima}

La provincia de San Juan está incluida en la gran Diagonal Árida Sudamericana (DAS) la que se prolonga desde el norte del Perú ( $5^{\circ}$ latitud sur) hasta el estrecho de Magallanes (52 $2^{\circ}$ latitud sur), abarcando la mayor parte del oeste argentino, a sotavento de la Cordillera de los Andes (Pereyra, 1996). La DAS ingresa en territorio argentino a los $27^{\circ}$ latitud sur en el borde oeste, hasta los $44^{\circ}$ latitud sur en la costa atlántica (Bruniard, 1982). Los ejes de mayor aridez se posicionan paralelos a los cordones submeridianos. Cuando los cordones montañosos alcanzan cotas de $2.000 \mathrm{~m}$ s.n.m. la franja más árida se desplaza hacia el Este debido al incremento de la influencia del Pacífico (al sur de Mendoza, $35^{\circ}$ latitud sur; Bruniard, 1982). La DAS constituye un límite genético que resulta de la propia distribución geográfica de los elementos del clima y de los cordones montañosos, que controla la distribución de las precipitaciones, el régimen de heladas y las provincias fitogeográficas, independientemente de la posición latitudinal (Bruniard, 1982).

El área de estudio se caracteriza por estar dividida en dos tipos climáticos: la zona del valle, donde se desarrolla el arroyo Papagayos y la zona de recarga conformada por la sierra de La Huerta-Las Imanas. La zona del valle presenta un clima de tipo BWwha de acuerdo a la clasificación de Köppen (Pereyra, 1996). Este clima se caracteriza por presentar un 
clima seco de desierto, con lluvias de tipo torrencial y temperaturas cálidas que se concentran en el verano (TMA mayor a $18^{\circ} \mathrm{C}$ y la del mes más cálido mayor a $22{ }^{\circ} \mathrm{C}$ ) e invierno frío (Pereyra, 1996). En cambio, la Sierra de La Huerta-Las Imanas presenta un clima seco de estepa del tipo BSwka. En esta zona las precipitaciones medias anuales superan las del valle, aunque las mismas también están concentradas en la época estival y la temperatura media anual es más fría (TMA inferior a $18^{\circ} \mathrm{C}$ y la media del mes más caluroso inferior a $18^{\circ} \mathrm{C}$; Pereyra, 1996).

Son pocas las estaciones meteorológicas cercanas a la zona de estudio con datos disponibles. Entre ellas, se utilizaron la estación de El Portezuelo, ubicada en la sierra de Chepes que bordea el sector NE de la salina de Mascasín y presenta un tipo climático similar al de la sierra y la estación de Chepes, ubicada en el valle al este del área de estudio. Los datos de estas estaciones meteorológicas reportan que en los meses de diciembre, enero, febrero y marzo se concentra la mayor cantidad de precipitaciones, mientras que en el invierno estas son escasas a nulas (INTA, 2016). Para el caso de la estación de Chepes se obtuvieron datos del Servicio Meteorológico Nacional desde 1908 hasta la actualidad, aunque con muchos intervalos sin medición. Sin embargo, se observa que la distribución de las precipitaciones es similar, con mayor concentración estival (Fig. 2).

Los suelos de la región han sido clasificados como Torriortentes típicos, que se desarrollan en los piedemontes, donde son sujetos a continuo drenaje. El desarrollo de estos Entisoles se relaciona con las condiciones climáticas áridas, su granulometría gruesa y drenaje imperfecto (Regairaz, 2000).

\section{Metodología}

La metodología usada en este estudio incluyó el tratamiento de imágenes satelitales Landsat TM 7 , descargadas del sitio Global Landcover facilities, el cual brinda imágenes satelitales ortorectificadas. Luego se aplicó la corrección por dispersión atmosférica (Sabins, 1997). En una segunda etapa se aplicaron combinaciones de bandas para discriminar las diferentes unidades geomorfológicas y estratigráficas del área de estudio y sus contactos. Se emplearon combinaciones de bandas para identificar diferentes sectores del arroyo Papagayos, como áreas de canales y áreas de llanura de inundación. Luego, se utilizaron técnicas de aumento de contraste para producir una mejor distribución de los números digitales (DN) en la imagen y resaltar aquellos detalles que no resultan perceptibles por el observador (Sabins, 1997).Y, finalmente, en la tercera etapa mediante la aplicación de cocientes y transformaciones, se intentó diferenciar subambientes dentro de la llanura de inundación discriminando áreas con mayor humedad, cubierta vegetal y suelos salinos.

Teniendo en cuenta el procesamiento de las imágenes satelitales, sumado a controles de campo, se realizó un mapa sedimentológico-geomorfológico detallado del arroyo Papagayos. Se identificaron y estudiaron desde el punto de vista sedimentológico las siguientes geoformas fluviales: canales principales, canales secundarios, diferentes tipos de barras fluviales, formas de lecho, y elementos de la llanura de inundación como albardones, lóbulos de desbordamiento, charcas, canales secundarios alimentadores de llanura de inundación y dunas. Estas geoformas fueron analizadas como elementos arquitecturales dentro del sistema distributario fluvial y en cada una de ellas se relevaron transectas sedimentológicas detalladas, describiéndose perfiles en las caras libres de las mismas, aplicando las metodologías de Allen (1983) y Miall (1996) (Tabla 1). Los elementos arquitecturales fueron definidos de acuerdo a su disposición espacial, morfología, arquitectura facial y jerarquía de superficies limitantes que los conforman (Miall, 1985, 1996). De acuerdo con Allen (1983) y Miall (1996) las superficies de $1^{\circ}$ y $2^{\circ}$ orden limitan sets y cosets, respectivamente; las superficies de $3^{\circ}$ orden indican reactivación de las corrientes fluviales, que producen modificaciones en el régimen de flujo pero no en el estilo de las macroformas. Para las superficies de $4^{\circ}$ orden, se utilizó la acepción de Tripaldi et al. (2001), quien divide la superficie de cuarto orden en tres reconociéndose las superficies $4 \mathrm{a}$, que describe el límite superior de macroformas con morfología preservada, resultando generalmente planas o convexas hacia arriba (Miall, 1988, 1996); las 4b, cóncavas hacia arriba o irregulares, que marcan las superficies basales de canales individuales incluidos en complejos de canales, y las 4c, irregulares o planas, como aquellas que limitan depósitos de canales menores o lóbulos de desbordamiento dentro de la planicie de inundación. Finalmente, se identificaron como superficies de $5^{\circ}$ orden las que limitan complejos de canales o grandes canales multiepisódicos (Miall, 1996). 


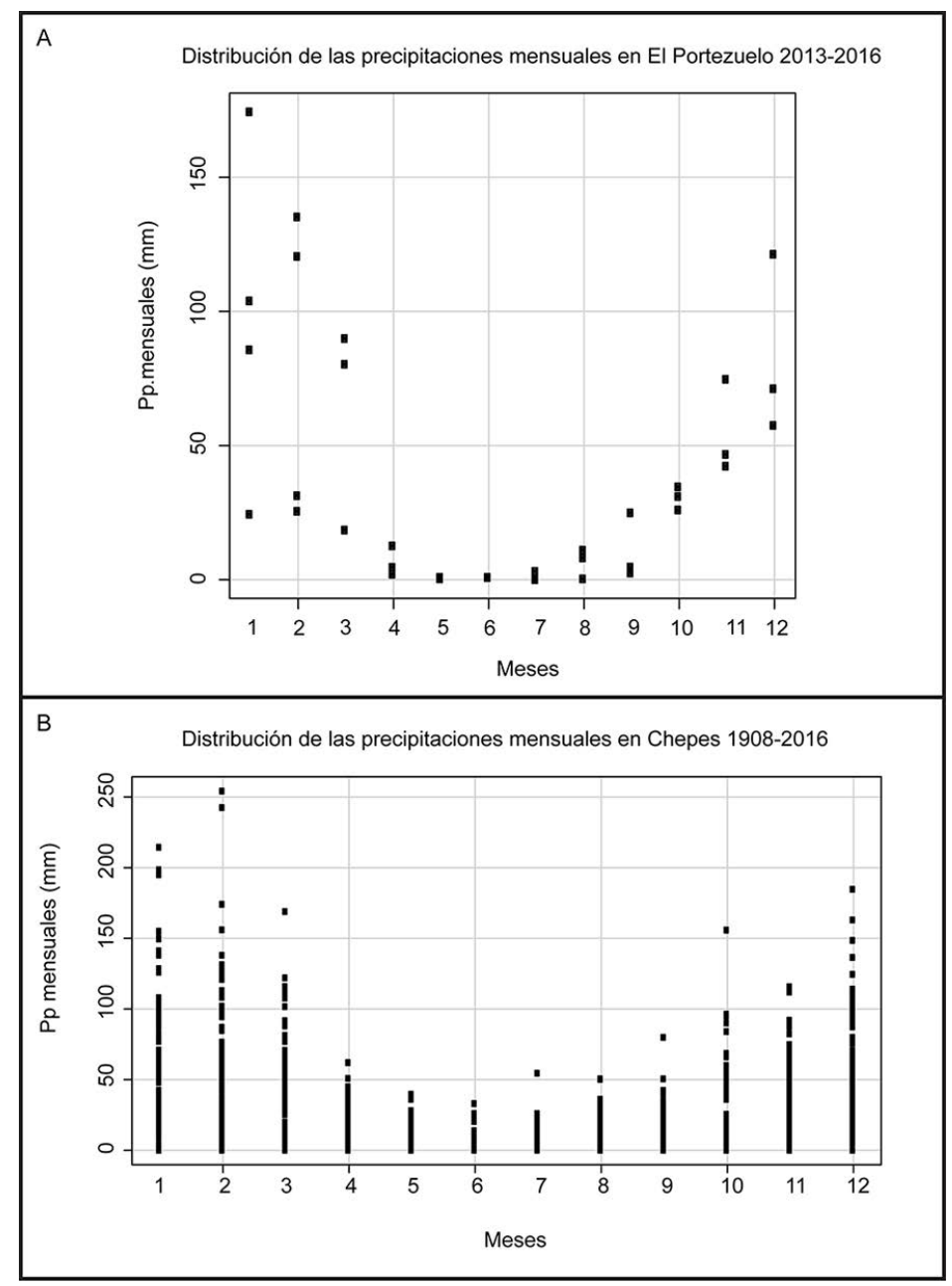

FIG. 2. Gráfico de distribución de las precipitaciones anuales en las estaciones meteorológicas cercanas al arroyo Papagayos. A. Estación meteorológica El Portezuelo ubicada en la sierra de Chepes; B. Estación meteorológica Chepes ubicada en el valle, al este de la salina de Mascasín.

En el análisis sedimentológico se utilizaron elementos arquitecturales definidos como macroformas producto del efecto acumulativo de la sedimentación a lo largo de periodos de decenas a miles de años (Jackson, 1975; Miall, 1996). La importancia de diferenciar elementos arquitecturales es que conforman macroformas observables en planta y en su conjunto, permiten la clasificación de los ambientes sedimentarios que forman el arroyo Papagayos desde un aspecto sedimentológico (Miall, 1996).

Por otra parte, se obtuvieron parámetros morfológicos de los distintos sectores del arroyo Papagayos para obtener una mejor caracterización del mismo. La sinuosidad del canal fue analizada siguiendo la metodología de Gumbricht et al. (2004) que consiste en analizar la variación de estos parámetros en diferentes escalas. En este caso se consideraron cuatro escalas de trabajo tomando segmentos de 2,1, 0,5 y 0,05 kilómetros. A través del SIG se obtuvieron las longitudes totales de los tramos. El cálculo de la sinuosidad se hizo a través de IS=thalweg/longitud del valle (Leopold y Wolman, 1957) para cada segmento, y se calculó la dimensión fractal del cauce principal para compararlo con el clásico IS (Gan et al., 1992). También se obtuvo la relación ancho/profundidad de los cauces activos a lo largo de los distintos sectores identificados en el SFD dentro del arroyo Papagayos. 
TABLA 1. LITOFACIES DE SFD DEL ARROYO PAPAGAYOS DE ACUERDO A LAS DEFINIDAS POR MIALL (1977, 1996). PARA LAS EÓlICAS SE USARON LAS DEFINIDAS POR HUNTER (1977) Y TRIPALDI Y LIMARINO (2008).

\begin{tabular}{cll}
$\begin{array}{c}\text { Código } \\
\text { de facies }\end{array}$ & \multicolumn{1}{c}{ Facies } & \multicolumn{1}{c}{ Descripción } \\
\hline Bci & $\begin{array}{l}\text { Bloques imbricados con } \\
\text { matriz arenosa. }\end{array}$ & $\begin{array}{l}\text { Se presentan en cuerpos lentiformes de dimensiones } \\
\text { métricas }(15 \text { de longitud por } 4 \mathrm{~m} \text { de ancho). Los } \\
\text { bloques son subredondeados a subangulosos y posee } \\
\text { dimensiones de } 0,70 \text { a } 1,20 \text { m. Están formados } \\
\text { por rocas metamórficas (anfibolitas, migmatitas) y } \\
\text { sedimentarias (areniscas y conglomerados). }\end{array}$ \\
Gci & $\begin{array}{l}\text { Ge presentan en cuerpos lenticulares de pequeñas } \\
\text { dimensiones (hasta } 0,50 \mathrm{~m} \text { de largo por } 0,20 \mathrm{~m} \text { de } \\
\text { ancho). Las gravas son subredondeadas y poseen } \\
\text { tamaños de hasta } 0,10 \mathrm{~m} \text {. La selección es buena. }\end{array}$ \\
& clastosoportadas. &
\end{tabular}

Gem Gravas macizas clastosoportado

Gmm Gravas macizas matriz soportadas.

Gh Gravas con estratificación horizontal.

$\mathrm{S}(\mathrm{G}) \mathrm{m} \quad$ Arenas gravosas macizas.

S(G)1 Arenas con laminación inclinada de bajo ángulo.

S(G)h Arenas gravosas con laminación horizontal difusa.

Arenas macizas.

Arenas con laminación cruzada de bajo ángulo. horizontal.
Bancos tabulares con espesores de 0,05 hasta $0,40 \mathrm{~m}$, y dimensiones de decenas de metros Los clastos son subredondeados, con tamaños de hasta $0,07 \mathrm{~m}$ en cuerpos de selección buena. Se presenta como: a) lentes de $1 \mathrm{~m}$ de largo por $0,50 \mathrm{~m}$ de ancho, b) y/o en grandes cuerpos linguoides con base plana.

Cuerpos lenticulares a lentiformes de $0,10 \mathrm{~m}$ de espesor, formados por clastos subredondeados a subangulosos de hasta $0,05 \mathrm{~m}$ de diámetro de selección moderada. La matriz es arenosa.

Se presentan en capas tabulares de hasta $0,20 \mathrm{~m}$ de espesor, formadas por clastos subrendodeados de hasta $0,02 \mathrm{~m}$ de diámetro, bien seleccionados.

Se disponen en bancos tabulares de 0,40 m. Están compuestos de arenas gruesas a medias, con clastos gravosos de hasta $0,07 \mathrm{~m}$ y a veces presentan troncos carbonizados. La selección es regular.

Bancos tabulares en espesores de 0,20 m de arenas medias a finas de selección buena con clastos de hasta $0,02 \mathrm{~cm}$ de tamaño.

Bancos tabulares en espesores 0,20 $\mathrm{m}$ de arenas finas de selección buena con clastos aislados de tamaño sábulo.

Se disponen en cuerpos linguoides de tamaños métricos. Están formados por arenas medias a finas con buena selección.

Bancos tabulares laminados de $0,15 \mathrm{~m}$ de espesor. Compuestos de arenas gruesas a medias, de selección buena.

Se dispone en bancos tabulares de hasta $0,20 \mathrm{~m}$ de espesor, están formados por arenas de grano grueso a fino, bien seleccionadas. En ocasiones se presenta con arenas gruesas.

Se disponen en bancos tabulares de unos 0,10 $\mathrm{m}$ de espesor; están formados por arenas medias a finas de buena selección.

Interpretación

Flujos fluidos o normales turbulentos que transportan bloques por rolido. La matriz arenosa es secundaria.

Flujos fluidos y turbulentos que transportan clastos por rolido.

Flujos fluidos o normales que generan formas de lecho longitudinal (barras de canal) y rellenan estructura de corte y relleno.

Flujos de granos hiperconcentrados no cohesivos.

Flujos fluidos, depósitos generados por el apilamiento de carpetas tractivas.

Flujos de granos

hiperconcentrado no cohesivos.

Flujos torrenciales en manto que generan condiciones de alto régimen de flujo.

Flujos torrenciales en manto. Flujos de alto régimen de flujo, flujo crítico. En algunos casos se presenta como depósitos de bajo régimen de flujo (caso PCS).

Flujos de granos

hiperconcentrados no cohesivos.

Depósitos formados en los estadios de régimen de flujo intermedio, humpback o lado stoss de dunas.

Depósitos de flujo de alto régimen de flujo, flujo crítico.

Flujos de intermedio a bajo régimen de flujo. Dunas transversales, óndulas de arena. 
Continuación tabla 1.

\begin{tabular}{lll}
\hline $\begin{array}{c}\text { Código } \\
\text { de facies }\end{array}$ & \multicolumn{1}{c}{ Facies } & \multicolumn{1}{c}{ Descripción } \\
\hline $\mathrm{St}$ & $\begin{array}{l}\text { Arenas con } \\
\text { entrecruzamiento en } \\
\text { artesa. }\end{array}$ & $\begin{array}{l}\text { Se disponen en bancos tabulares de hasta } 0,30 \mathrm{~m} \\
\text { espesor; están formados por arenas medias a finas } \\
\text { bien seleccionadas. }\end{array}$ \\
$\mathrm{Sr}$ & $\begin{array}{l}\text { Arenas con laminación } \\
\text { ondulítica de corriente. }\end{array}$ & $\begin{array}{l}\text { Forman capas de } 0,01 \mathrm{a} 0,10 \mathrm{~m} \text { de espesor. A vec } \\
\text { es ascendente. Arenas finas, con buena selección. } \\
\text { Techos de ondulitas preservados. }\end{array}$ \\
$\mathrm{F}(\mathrm{G}) \mathrm{m}$ & $\begin{array}{l}\text { Fango macizo con clastos } \\
\text { aislados. }\end{array}$ & $\begin{array}{l}\text { Bancos tabulares de } 0,60 \mathrm{~m} \text { de espesor, gránulos } \\
\text { aislados y escasos clastos de hasta } 0,07 \mathrm{~m} \\
\text { "suspendidos". También presentan troncos. Los } \\
\text { bancos poseen bases planas y techos planos } \\
\text { a convexos en las que se observan grietas de } \\
\text { desecación pequeñas. }\end{array}$ \\
\hline
\end{tabular}

F(S)m Fango macizo con gránulos aislados.

F(S)1 Fangos laminados con gránulos aislados.

Fm Fangos macizos.

F1 Fangos con laminación horizontal y/o ondulítica de pequeña escala.

Flc Fangos con laminación horizontal en cortinas de fango.

Ev Láminas de sales.

$\mathrm{Fl}_{\mathrm{w}} \quad$ Fangos laminados de bajo régimen de flujo; ondulitas de oscilación.

Sre $\quad$ Ondulas de arena: gruesa a sábulo, mal seleccionadas con difusa gradación inversa de intralámina; o fina a muy fina selección moderada con gradación inversa.

Sg Arenas medias a finas con gradación inversa.

Slg Arenas con laminación entrecruzada de muy bajo ángulo con gradación inversa.

Shm Arenas con laminación horizontal a difusa, internamente macizas.
Bancos tabulares de 0,30 $\mathrm{m}$ de espesor, con granos de arena o gránulos aislados. Los bancos presentan bases planas y el techo es levemente convexo.

Bancos tabulares de $0,20 \mathrm{~m}$ de espesor con granos aislados de arenas.

Estratos tabulares macizos de 0,40 a $0,70 \mathrm{~m}$ de espesor compuestos por fangos arcillosos-arenosos. $\mathrm{El}$ aspecto macizo del estrato puede relacionarse con la intensa bioturbación que presentan .

Forman estratos de hasta $0,01 \mathrm{~m}$ de espesor. Generan grietas de desecación.

Láminas que se depositan en charcos de agua de canales activos. Generan cortinas de fango.

Pueden presentarse como parches milimétricos de sales hasta llegar al orden del centímetro. También aparece como una cubierta en raíces.

Ondulas simétricas de hasta $0,10 \mathrm{~m}$ de diámetro.

Depósitos de tamaño pequeño dispuestos en los canales activos, tipos parches de arena (Tripaldi y Limarino, 2008). También aparecen cubriendo dunas mayores y en las áreas de interdunas.

Se observan en las crestas de óndulas de depósitos de barras fluviales como retrabajamiento eólico que genera láminas de arena con gradación inversa.

Arenas finas bien seleccionadas con granos oscuros en la crestas de las óndulas. Se presentan en bancos tabulares a lentiformes, en cuerpos de hasta $2 \mathrm{~m}$ de espesor con perfil asimétrico.

Arenas muy finas con laminación horizontal. Se presentan en dunas longitudinales.

\section{Interpretación}

Flujos de intermedio a bajo régimen de flujo. Dunas de crestas sinuosas.

Depositadas en condiciones de bajo régimen de flujo.

Flujos de barro híperconcentrado cohesivos. Se presentan en lóbulos de desbordamientos, y lóbulos terminales.

Flujos de barro híperconcentrado cohesivos. Típicos de albardones.

Flujos menguantes en la etapa final de la inundación.

Suspensión. Depósitos de flujos de barros en zonas de desbordamiento.

Depósitos de flujos menguantes en la etapa final de la inundación.

Depósitos de flujos menguantes en la etapa final de la inundación.

Evaporación de agua procedente de nivel freático alto de lluvias.

Depósitos formados en cuerpos de agua estacionales, asociados al movimiento del agua por la acción del viento.

Migración de óndulas de arena o de gránulos clastos transportados por reptación y granos por saltación (Sharp, 1963; Hunter, 1977).

Migración de óndulas de arena.

Migración de óndulas de arena.

Migración de dunas de crestas rectas, con caras de sotavento dominadas por caída y flujos de granos. 


\section{Resultados}

\subsection{Procesamiento de imágenes satelitales}

La combinación de bandas en el espectro visible (321), que surgió del procesamiento de imágenes Landsat TM 7, arrojó una imagen con poco contraste. Por ello, se aplicaron diferentes combinaciones que pudieran resaltar el SFD del resto de los depósitos y su zonación interna (Fig. 3). La combinación de bandas 741 resaltó mejor los distintos materiales, vegetación y elementos del área de estudio, ya que la banda 7 refleja mejor materiales arcillosos y salinos (Fig. 3A, Mougenot et al., 1993). Con la aplicación de aumento de contraste por ecualización, se distinguieron con más claridad aquellas zonas con materiales gravosos, de las zonas con materiales limosos y arcillosos, y las formadas por basamento (rocas sedimentarias y cristalinas). También, se resaltaron mejor las zonas más vegetadas, de aquellas menos vegetadas, diferenciando distintos sectores de la salina. Debido a las condiciones climáticas áridas de la zona de estudio, la cubierta de la vegetación nativa es aislada y tiende, en general, a concentrarse en los cauces temporarios y en aquellas zonas donde la napa freática se encuentra cercana a la superficie. Esto favorece poder resaltar la red de drenaje a través de combinaciones de bandas que destaquen la vegetación, como la combinación 453 (Carrasco Pereira et al., 2005; Fig. 3B).

Por otra parte, se aplicó el cociente de las bandas 5/7 para un mejor resalto de sales (cloruros-anhidrita), que son las que forman la salina de acuerdo con los datos de pozos (Criado Roque et al., 1981; Mougenot et al., 1993). El cociente 5/7 brindó una imagen con poco contraste, aunque se distinguieron aquellos sectores con sales en blanco como en la salina y en algunas porciones de la llanura de inundación del SFD, especialmente cuando los materiales son más finos (Fig. 3C).

Finalmente, con el fin de poder discriminar diferentes zonas en la llanura de inundación (sectores drenados y mal drenados, charcos con acumulación de sales) del SFD del arroyo Papagayos, se utilizó la transformación del índice SAVI. Este índice combina bandas del infrarrojo cercano y el espectro visible para estimar la calidad y vigor de la vegetación, y se aplica en regiones áridas porque tiene en cuenta la influencia del suelo por su color y brillo (asignando un valor de $L$ de 0,5; Huete, 1988; Sánchez Rodríguez et al.,
2000). Este índice de vegetación arroja valores que oscilan entre - 1 y 1 , siendo aquellos valores menores de cero los que indicarían ausencia de vegetación (Carvacho Bart y Sánchez Martínez, 2010). Los datos obtenidos de la aplicación del índice SAVI muestran que un $7 \%$ presenta muy escasa a nula presencia de vegetación; el $41 \%$ de la superficie presenta valores entre 0,178370 y 0,327939 , los que se distribuyen en el piedemonte y en la llanura de inundación del sector medio. Por otro lado, el $41 \%$ presenta valores entre 0,327940 y 0,477508 y se ubican en las zonas elevadas topográficamente (sierras), en el sector distal del lóbulo terminal y en el borde costero de la salina, donde aflora la napa freática. Un $9 \%$ presenta valores de 0,477509 y 0,627078 que corresponden a la cubierta vegetal que se dispone en los cauces temporarios principales. Finalmente, el $2 \%$ restante, presenta valores mayores a 0,627079 , los que se ubican como asomos aislados en los cauces principales y en los cauces de la plataforma arenosa de la salina donde se junta el agua de escurrimiento superficial con la napa.

De acuerdo con la distribución y características de la vegetación podemos dividir al SFD del arroyo Papagayos en al menos tres zonas, desde el ápice, donde pierde el confinamiento, hasta la salina: a) una zona proximal donde dominan valores de SAVI muy bajos a bajos entre 0,028 y 0,32 ; b) una media donde dominan valores de SAVI entre 0,32-0,47 en el cauce principal y en la zona de inundación valores más bajos de 0,17 a 0,32 ; y c) una distal que puede dividirse en dos sectores, una proximal que presenta valores bajos de 0,17 a 0,32 , y un sector distal que alcanza valores mayores de 0,32 a 0,47 del índice SAVI que es donde aflora napa freática (Fig. 4).

\subsection{Zonación del arroyo Papagayos}

El arroyo Papagayos presenta su cuenca alimentadora en el borde occidental y sur de las sierras de La Huerta-Imanas, y discurre a lo largo de 2,3 $\mathrm{km}$ por una estrecha quebrada hasta que pierde el confinamiento. A partir de este punto, el arroyo atraviesa el piedemonte a lo largo de $11 \mathrm{~km}$ hasta formar un cono de unos $20 \mathrm{~km}$ de radio y un ancho máximo de $10 \mathrm{~km}$. Abarcando un área total de $33,12 \mathrm{~km}^{2}$ (Fig. 5).

El mapeo sedimentológico-geomorfológico detallado permitió identificar diferentes elementos 

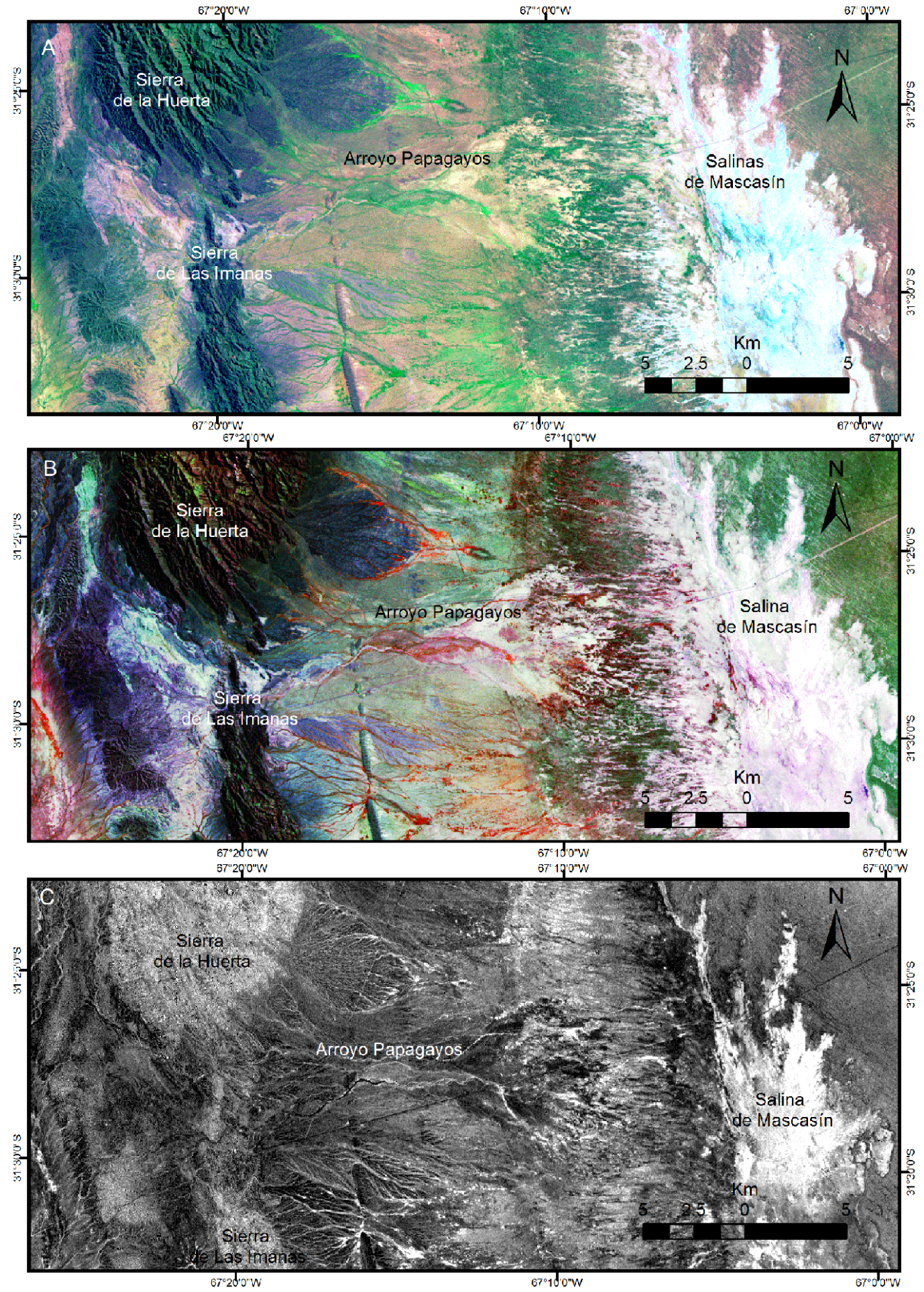

FIG. 3. Combinaciones de bandas Landsat TM 7 en RGB. A. Combinación 741. Resalta los materiales arcillosos y salinos en tonos claros a blancos; B. Combinación 453. Destaca especialmente la vegetación en rojo y la red de drenaje distributaria del arroyo Papagayos; C. Cociente de bandas 5/7 para el área de estudio. Permite resaltar las zonas con mayor contenido de sales (zonas de color blanco) que se observan como un moteado en la zona distal del abanico del arroyo Papagayos y con una distribución más uniforme en la salina. 

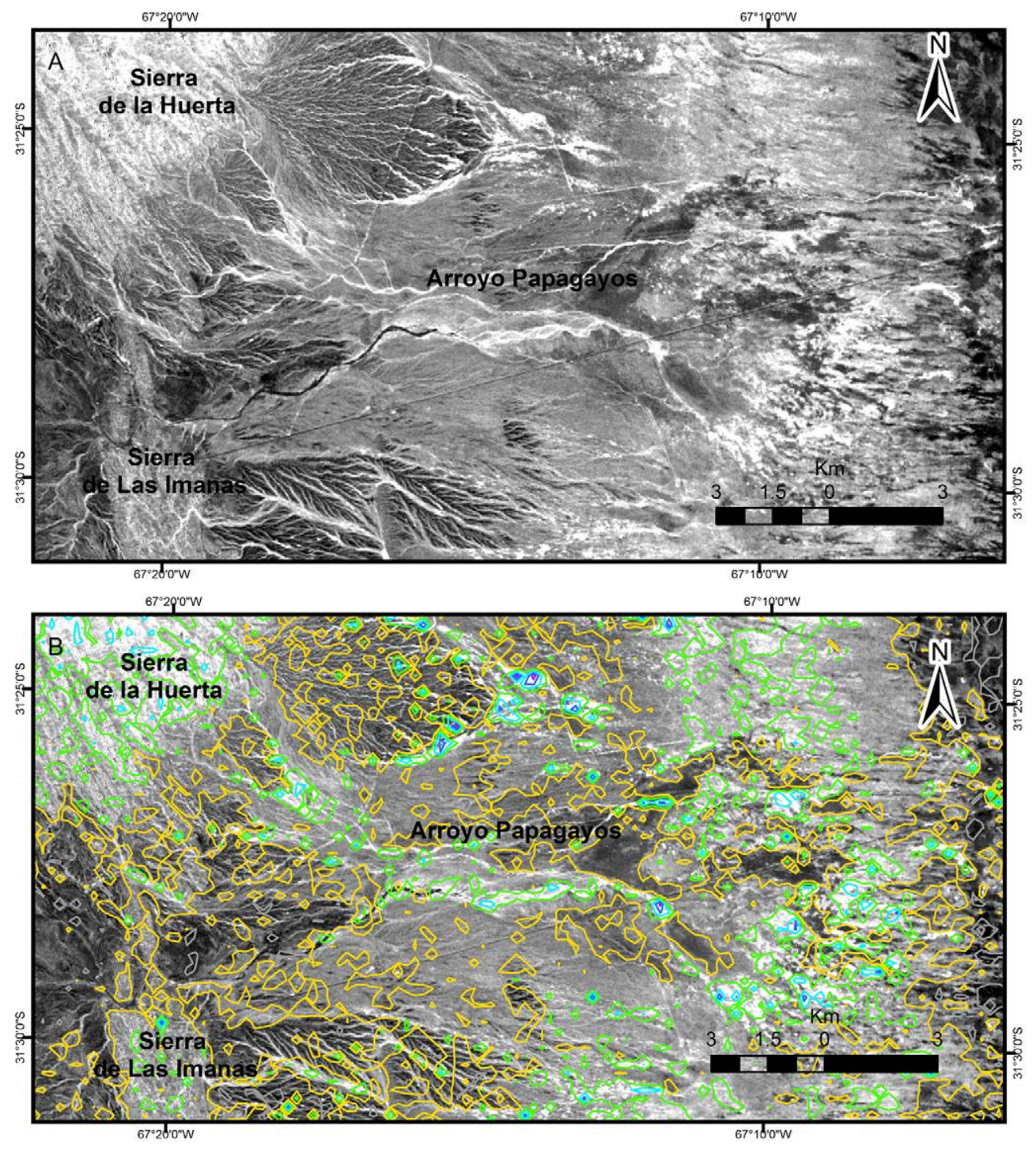

Índice SAVI

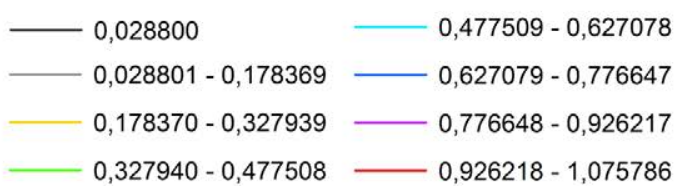

FIG. 4. Aplicación de índice de vegetación ajustado SAVI. A. Imagen resultante de la aplicación del índice SAVI. Nótese que las zonas más claras son las que presentan valores más altos del índice SAVI; B. Mapa de isolíneas de la distribución del índice SAVI en la zona de estudio.

arquitecturales que presenta el SFD del arroyo Papagayos, y con ellos caracterizar el sistema depositacional (Fig. 5). El SFD del arroyo Papagayos ha sido separados en tres zonas principales: a) Zona
1 o proximal, b) Zona 2 o media y c) Zona 3 o distal. Se reconoce, además, Zona 4, que resulta transicional entre el SFD y la salina de Mascasín. Los valores sinuosidad para cada zona se expresan en la tabla 2. 


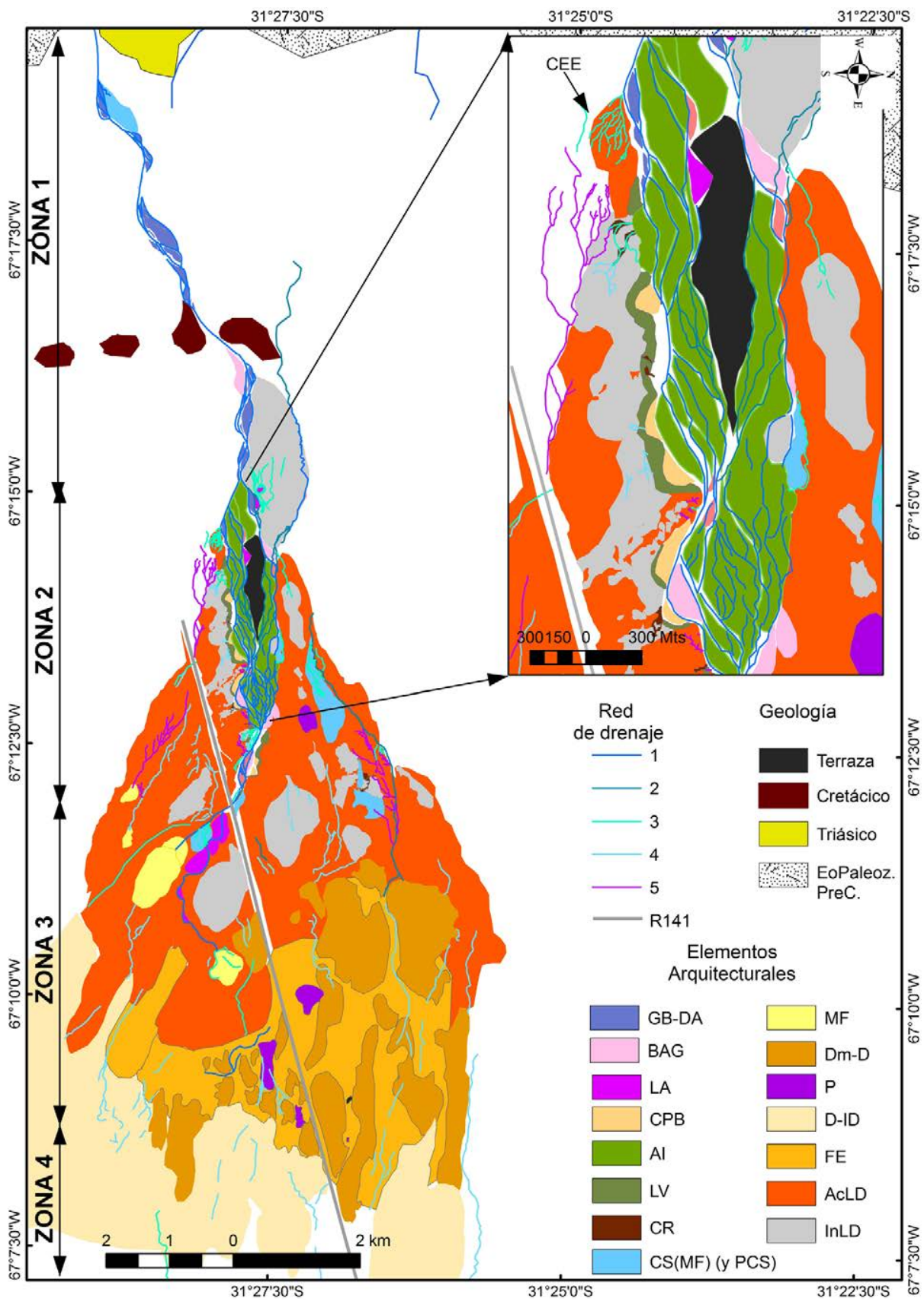

FIG.5. Mapa geomorfológico y sedimentológico del SFD del arroyo Papagayos en donde se identifican los elementos arquitecturales que lo componen, la red de drenaje de la faja de canales y de la llanura de inundación. Referencias: Red de Drenaje: 1 canales activos principales, 2 canales secundarios activos, 3 canales alimentadores de llanura de inundación conectados a los canales principales, 4 canales de la llanura de inundación, 5 red de canales generados por erosión retrocedente, R141: Cauce paralelo a la ruta 141. Elementos Arquitecturales: GB-DA: Barras longitudinales y barras longitudinales vegetadas, BAG: barra alterna gravosa, LA: barra de acreción lateral, CPB: barra counterpoint bar, AI: área intercanal, LV: albardones, CR: canales alimentadores de lóbulos de desbordamiento, CS(MF) (y PCS): lóbulos de desbordamiento, se incluyen lóbulos de desbordamiento proximales, MF: lóbulos terminales, Dm-D: dunas menores y dunas, P: charcas, D-ID: dunas e interdunas, FE: elementos arquitecturales indiferenciados en zona de interacción fluvio-eólica, AcLD: elementos arquitecturales indiferenciados (CS-CR) en llanura de inundación, InLD: elementos arquitecturales indiferenciados (CS-CR) en sectores inactivos de la llanura de inundación. 
TABLA 2. ÍNDICE DE SINUOSIDAD (IS) Y DIMENSIÓN FRACTAL (D) DEL CAUCE PRINCIPAL DEL ARROYO PAPAGAYOS, EN DIFERENTES ESCALAS (LONGITUDES EN KILÓMETROS).

\begin{tabular}{cccc}
\hline & Zona 1 & Zona 2 & Zona 3 \\
\hline Long. total $(\mathrm{km})$ & 9,63 & 5,36 & 3,57 \\
Total recto $(\mathrm{km})$ & 8,69 & 4,86 & 2,61 \\
Segmento: $1 \mathrm{~km}$ & 9 & 5 & 3 \\
Segmento: $0,5 \mathrm{~km}$ & 9,5 & 5 & 3,5 \\
Segmento: $0,05 \mathrm{~km}$ & 9,6 & 5,35 & 3,55 \\
IS $(1 \mathrm{~km})$ & 1,04 & 1,03 & 1,15 \\
IS $(0,5 \mathrm{~km})$ & 1,09 & 1,03 & 1,34 \\
IS $(0,05 \mathrm{~km})$ & 1,10 & 1,10 & 1,36 \\
IS (total) & 1,1 & 1,1 & 1,36 \\
Fractal (D) & 1,02 & 1,04 & 1,07 \\
\hline
\end{tabular}

\subsubsection{Zona 1 o proximal}

La zona 1 se define entre las coordenadas $31^{\circ} 29^{\prime} 12,87^{\prime \prime}$ S-67 $17^{\circ} 46,04$ " O y $31^{\circ} 27^{\prime} 51,52^{\prime \prime}$ S$67^{\circ} 15^{\prime} 11,71$ ' O, con una pendiente de $0,9 \%$, en la que se observa que el SFD del arroyo Papagayos está formado por un río principal multicanalizado con baja sinuosidad (Tabla 2). A lo largo del cauce aparecen barras gravosas de gran magnitud, ubicadas en los sectores centrales y laterales del mismo (Fig. 5). En forma secundaria, al norte del curso principal, se observa un curso fluvial de menor orden con baja sinuosidad, cuya naciente corresponde a una cuenca de drenaje menor y que alimentan al sistema del SFD en forma esporádica y secundaria en esta zona. Este sector representa un $48 \%$ de la distancia total recorrida por el arroyo Papagayos, medida desde el momento que pierde el confinamiento. El ancho del cauce varía de $63 \mathrm{~m}$ en el borde del frente montañoso a valores máximos de $166 \mathrm{~m}$ en las zonas más sinuosas. La carga es de tipo gravosa principalmente y arenosa en forma secundaria. Las litofacies definidas en este sector son Gcm, Gmm, Gci, S(G)m, S(G)h, Sh, Sl, Fm, Sre (Tabla 1) y se disponen formando diferentes elementos arquitecturales (Anexo 1).

Los elementos arquitecturales reconocidos en la zona 1 incluyen formas de lecho gravosas y arenosas (SGB-LS, Fig. 6a, b, c), hoyos HO, barras longitudinales (GB, Figuras 6d, e, f), barras longitudinales vegetadas (DA, Fig. 6g, h, i) y barras alternas gravosas (BAG, Fig. 6j, k). El cauce del arroyo Papagayos está tapizado por gravas y arenas del elemento SGB-LS, que se disponen como mantos o lenguas. Es frecuente observar cortinas de fango y evaporitas sobre las litofacies arenosas y retrabajamiento eólico (Fig. 6b y c). Las barras longitudinales (GB) están formadas por barras gravosas bajas que también presentan arenas gruesas (Fig. 6e). Las barras longitudinales vegetadas (DA) son más altas que las barras GB, presentan árboles y abundantes arbustos en las mismas. Las barras DA están formadas por un núcleo gravoso y por encima una sucesión de litofacies arenosas medias que una vez depositadas son retrabajadas por el viento. Las barras alternas gravosas (BAG) se ubican en los bordes del cauce y están formadas por bloques y una matriz secundaria arenosa (Anexo 1). En la llanura de inundación se identificaron lóbulos de desbordamiento proximales (PCS, Fig. 7) compuestos por capas heterolíticas de gravas finas y arenas gruesas. En general, el índice SAVI en esta zona es nulo por ausencia de vegetación, aunque presenta valores bajos $(0,17$ a 0,32 ) en algunos elementos arquitecturales como las barras longitudinales gravosas (DA) y los lóbulos de desbordamiento proximales (PCS).

\subsubsection{Zona 2 o media}

La zona 2 abarca el área definida entre las coordenadas $31^{\circ} 27^{\prime} 51,52$ " S-67 $7^{\circ} 15^{\prime} 11,71^{\prime}$ " O y $31^{\circ} 27^{\prime} 49,65^{\prime \prime}$ S $-67^{\circ} 12^{\prime} 2,53^{\prime \prime} \mathrm{O}$, con una pendiente de $0,64 \%$, que se define desde el punto en que el cauce principal del arroyo Papagayos, se bifurca en dos tramos, ambos de tipo multicanalizados, 


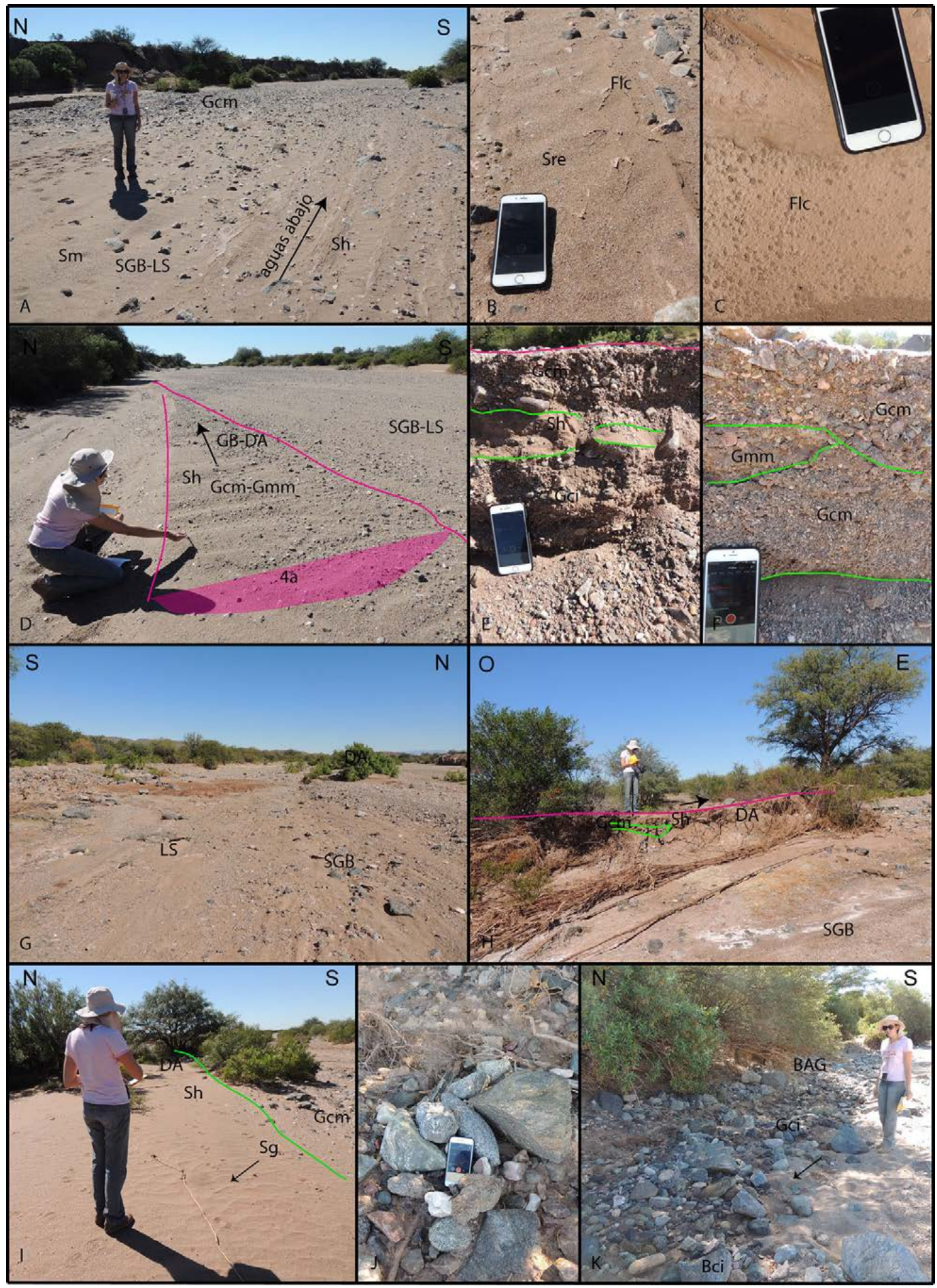

FIG. 6. Principales elementos arquitecturales reconocidos en la zona 1. Fotografías A-C. Elemento SBG-LS; D-F. Elemento GB; G-I. Elemento DA; J-K. Elemento BAG. La ubicación espacial de los elementos y su morfología en planta pueden observarse en la figura 5. La descripción de las litofacies mencionadas en la figura se encuentra en la tabla 1. SGB-LS: formas de lecho gravo-arenosas, GB: barras longitudinales, DA: barras longitudinales vegetadas, BAG: barras alternas gravosas. 


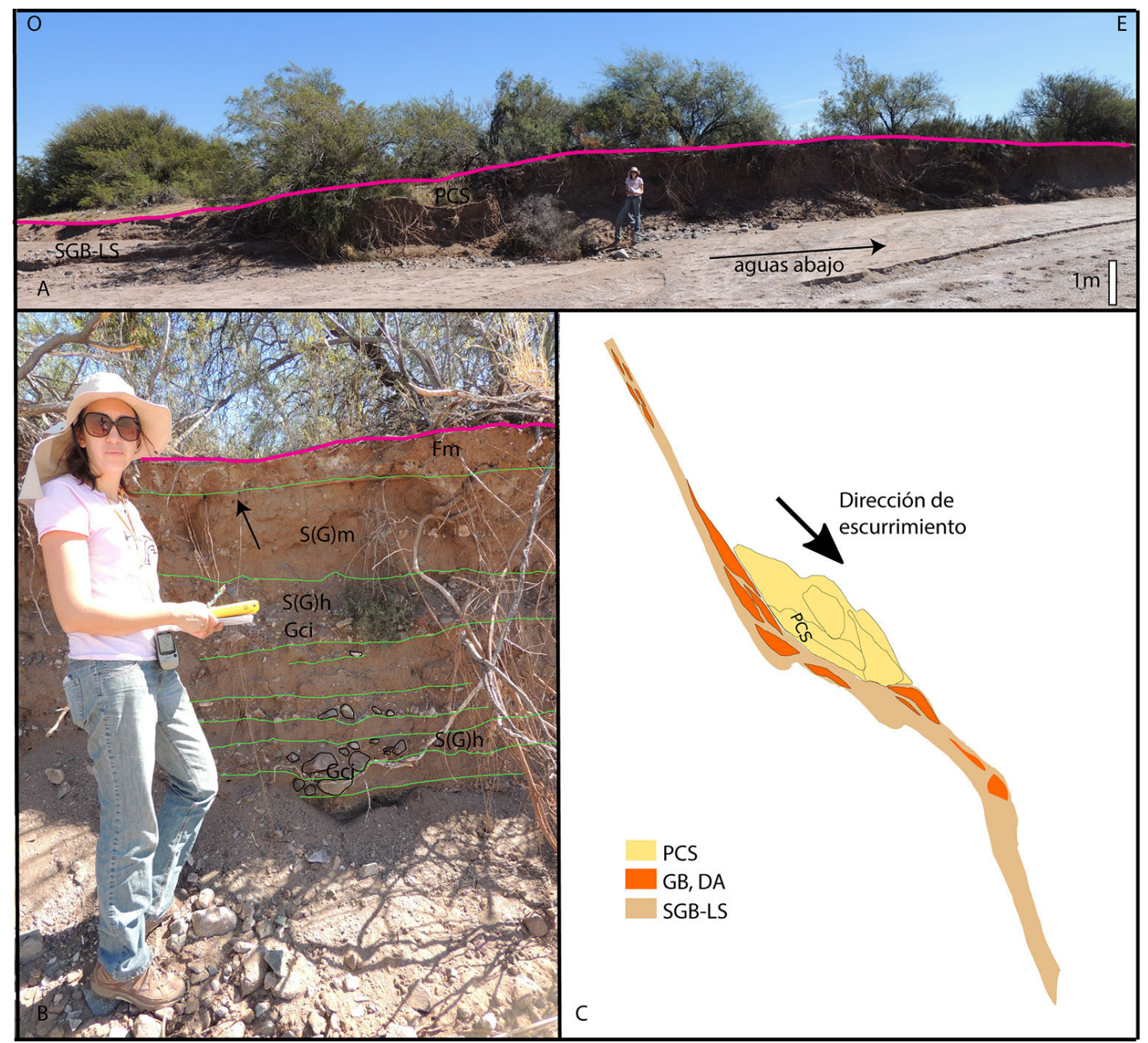

FIG. 7. Elemento arquitectural "Lóbulo de desbordamiento proximal" (PCS). A. Sección longitudinal; B. Perfil; C. Esquema en planta. La ubicación espacial de los elementos y su morfología en planta pueden observarse en la figura 5. La descripción de las litofacies mencionadas en la figura se encuentra en la tabla 1.

entre los que se desarrolla una amplia área rellena de materiales areno-gravosos y arcillosos. En esta zona los depósitos del arroyo Papagayos generan un gran lóbulo con forma de abanico levemente convexo, que se amplía hacia la zona 3 (Fig. 5). Este sector representa un $28 \%$ de la distancia recorrida por el arroyo Papagayos medida desde la bifurcación del cauce principal. El ancho del cauce principal disminuye a $35 \mathrm{~m}$, llegando a solo $10 \mathrm{~m}$ en algunos sectores. La relación de sinuosidad se mantiene constante y la dimensión fractal aumenta levemente con respecto a la zona 1 (Tabla 2). La carga de los cauces es de tipo gravo-arenosa. Las litofacies definidas en este sector son Gcm, Gci, Gh, Sl, St, Sh, Flc, Fm, F(G)m, F(S)m (Tabla 1) $\mathrm{y}$ se disponen formando diferentes elementos arquitecturales (Anexo 1). Hacia la porción distal, la llanura de inundación tiende a ser más plana y surcada por escasos canales de pequeño porte, principalmente erosivos.

En esta zona el arroyo Papagayos se bifurca en varios cauces separados principalmente por barras longitudinales vegetadas, generando áreas de intercanal estables con abundante vegetación arbórea y arbustiva (Fig. 5). En sectores donde el cauce es más sinuoso se observan las counter point bars. Los elementos 
arquitecturales reconocidos en el área canalizada están dominados por arenas y gravas. Una característica distintiva del área canalizada y el área de intercanal es la abundante vegetación, reflejada en valores bajos $(0,32)$ a altos $(0,77)$ del índice SAVI.

Los elementos arquitecturales del área canalizada son: formas de lecho arenosas (SB, Fig. 8a, b), barras longitudinales arenosas (BLA), hoyos (HO), barras longitudinales vegetadas (DA, Fig. 8c, d, e, f) y counter point bars (CPB, Fig. $8 \mathrm{e}, \mathrm{g}$ y h). En cambio, en comparación con la zona 1, en la zona 2 hay un notable incremento de los elementos arquitecturales de la llanura de inundación. Aquí se reconocen sistemas de canales entrelazados embrionarios (CEE), albardones (LV, Fig. 9a, b, $\mathrm{c}, \mathrm{d}, \mathrm{e})$, canal de lóbulo de desbordamiento (CR, Fig. 10a, b), lóbulos de desbordamiento ( $\mathrm{CS}_{(\mathrm{MF})}$, Fig. $10 \mathrm{c}$, d) y canales secundarios por erosión retrocedente $(\mathrm{CHm}$, Fig. 10 e, f). Las litofacies dominantes son arcillo-arenosas. Los albardones alcanzan alturas de 1,5 a $2 \mathrm{~m}$ y generan una clara separación topográfica del área canalizada del área de llanura de inundación. La llanura de inundación está dominada por la ocurrencia de procesos de acreción de lóbulos de desbordamiento, que prácticamente se distribuyen en toda el área de inundación. La presencia de litofacies $\mathrm{F}(\mathrm{S}) \mathrm{m}$ y $\mathrm{F}(\mathrm{G}) \mathrm{m}$ en los lóbulos de desbordamiento se asocia con la ocurrencia de flujos de barro, los que se generan asociados a mecanismos de infiltración durante el transporte y concentración de la matriz arcillosa (Anexo 1, Shultz, 1984). El índice SAVI se distribuye con valores bajos $(0,17$ a 0,32$)$ en los lóbulos de desbordamiento y medios a altos en los albardones $(0,47$ a 0,62$)$.

\subsubsection{Zona 3 o distal}

La zona 3 se define entre las coordenadas $31^{\circ} 27^{\prime} 49,65^{\prime \prime}$ S $-67^{\circ} 12^{\prime} 2,53^{\prime \prime}$ O y $31^{\circ} 27^{\prime} 28,46$ ” S$67^{\circ} 8$ '33,80" O, con una pendiente muy baja, de 0,4 . El cauce principal del arroyo Papagayos se vuelve un único cauce que desarrolla inicialmente un tramo recto y luego incrementa su sinuosidad (Tabla 2). Finalmente se pierde infiltrándose en la llanura de inundación. Este sector representa un $24 \%$ de la distancia total recorrida por el arroyo Papagayos medida a partir del cambio a un único cauce fluvial. El ancho del cauce disminuye a valores de 25 a $12 \mathrm{~m}$. La carga dominante es de tipo areno-fangosa (limoarcilloso) y, en menor medida, gravosa. La zona 3 puede ser dividida a su vez en dos grandes sectores: uno dominado por la depositación del SFD del arroyo Papagayos con escasa interacción eólica y otro con intensa interacción eólica producto de la invasión de los depósitos del arroyo Papagayos en la faja costera de la salina (Fig. 5). Las litofacies definidas en este sector son Gm, S(G)l, S(G)m, St, Sh, Sm, Sr, Fl, $\mathrm{F}(\mathrm{G}) \mathrm{m}$, Ev, Slg (Tabla1).

En la zona 3 el área canalizada está representada por cuatro elementos arquitecturales (Anexo 1) formados por litofacies areno-arcillosas identificadas como formas de lecho arenosas (SB, Fig. 11a), barras de acreción lateral arenosas (LA, Fig. 11b, c, d, e), mantos de arenas laminadas (LS, Fig. $11 \mathrm{f}, \mathrm{g}$ ) y hoyos (HO).

La llanura de inundación está organizada en seis elementos arquitecturales (Anexo 1) que son albardones (LV, Fig. 12a), lóbulos de desbordamiento $\left(\mathrm{CS}_{\mathrm{MF}}\right)$, lóbulos de desbordamiento terminal (MF, Fig. 12b, c, d), canales secundarios de carga arenolimosa (CHd-LS, Fig. 12e), dunas menores (Dm, Fig. 12f) y charcas (P). Los procesos sedimentarios están representados por acreción de lóbulos de desbordamiento y lóbulos de desbordamiento terminales con participación de flujos de barro, acreción vertical de finos, precipitación de evaporitas y migración de óndulas eólicas. El índice SAVI presenta valores bajos $(0,17$ a 0,32$)$ en la llanura de inundación, alcanzando valores altos $(0,62)$ en los lóbulos de desbordamiento terminales cercanos al canal activo.

\subsubsection{Zona 4}

La zona 4 se define entre las coordenadas $31^{\circ} 27^{\prime} 28,46^{\prime \prime}$ S $-67^{\circ} 8^{\prime} 33,80^{\prime \prime}$ O y $31^{\circ} 26^{\prime} 27,68^{\prime \prime}$ S y $67^{\circ} 5$ '34,76" O y corresponde a una zona de transición demarcada entre la finalización de los depósitos del SFD del arroyo Papagayos y la parte central de la salina (Fig. 5). Los límites entre la zona 3 y la 4, estarían demarcados entre la zona de afloramiento de la napa freática y el sector dominado por la agradación vertical de finos y sales en la salina, al que se suma la intervención eólica. Esta zona está representada por una estrecha franja de unos $2 \mathrm{~km}$ de ancho, y una pendiente de $0,35 \%$ en donde domina la acumulación de sedimentos clásticos muy finos en la época de lluvias (verano) y sales en la época donde no llegan sedimentos clásticos transportados por el arroyo Papagayos y otras fuentes fluviales. Esta franja está surcada 


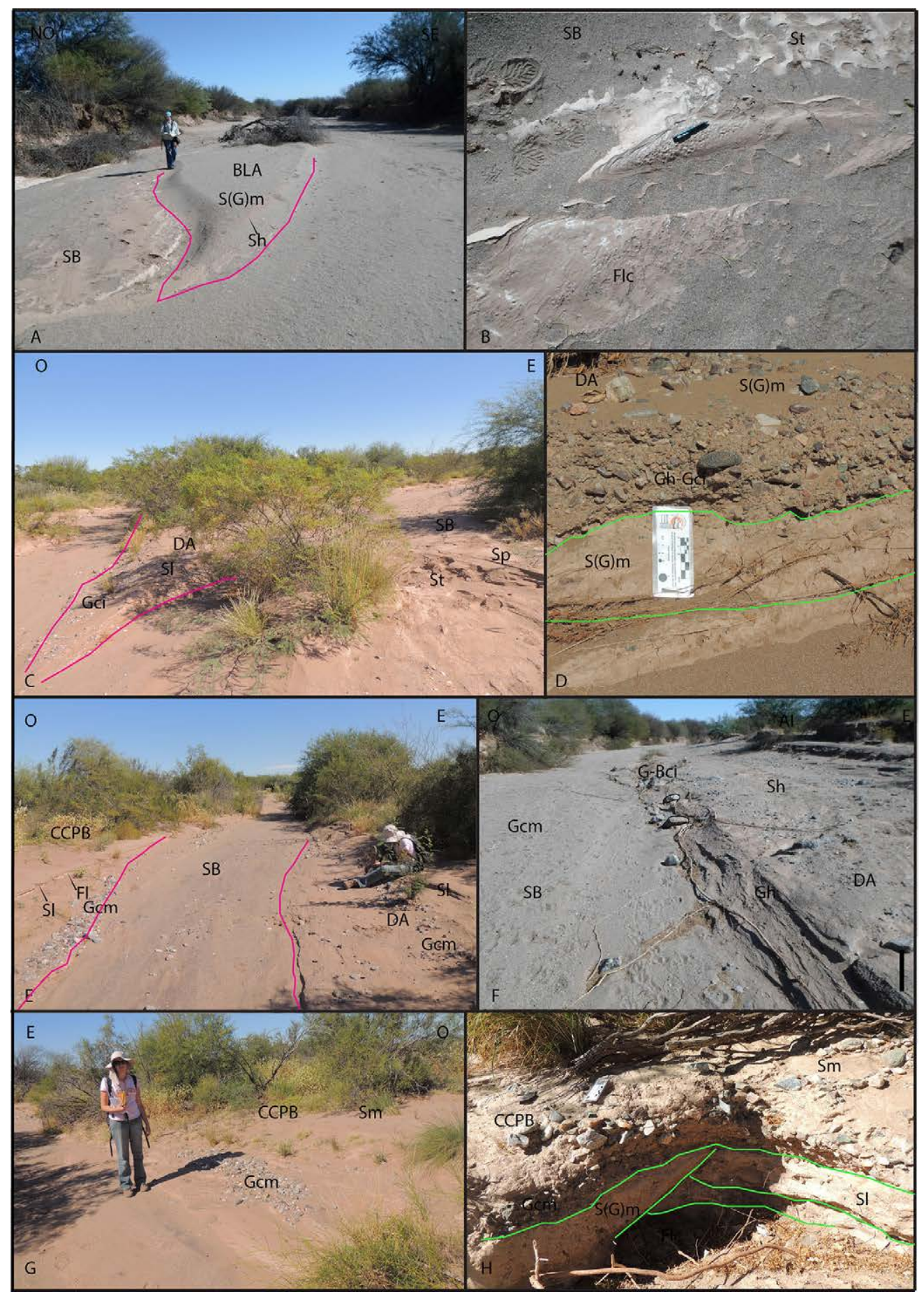

FIG. 8. Principales elementos arquitecturales de la faja de canales de la zona 2. A. Elemento BLA y SB; B. Detalle de litofacies del elemento SB; C. Elemento DA y SB; D. Detalle de elemento DA; E. Relación lateral entre elementos DA, SB y CPB; F. Elemento DA; se destaca un bloque aislado de unos 0,70 m; G-H. Elemento CPB y detalle de litofacies. La ubicación espacial de los elementos y su morfología en planta pueden observarse en la figura 5. La descripción de las litofacies mencionadas en la figura se encuentra en la tabla 1. BLA: barra longitudinal arenosa, SB: formas de lecho arenosa, DA: barra longitudinal vegetada, CPB: counter point bar. 


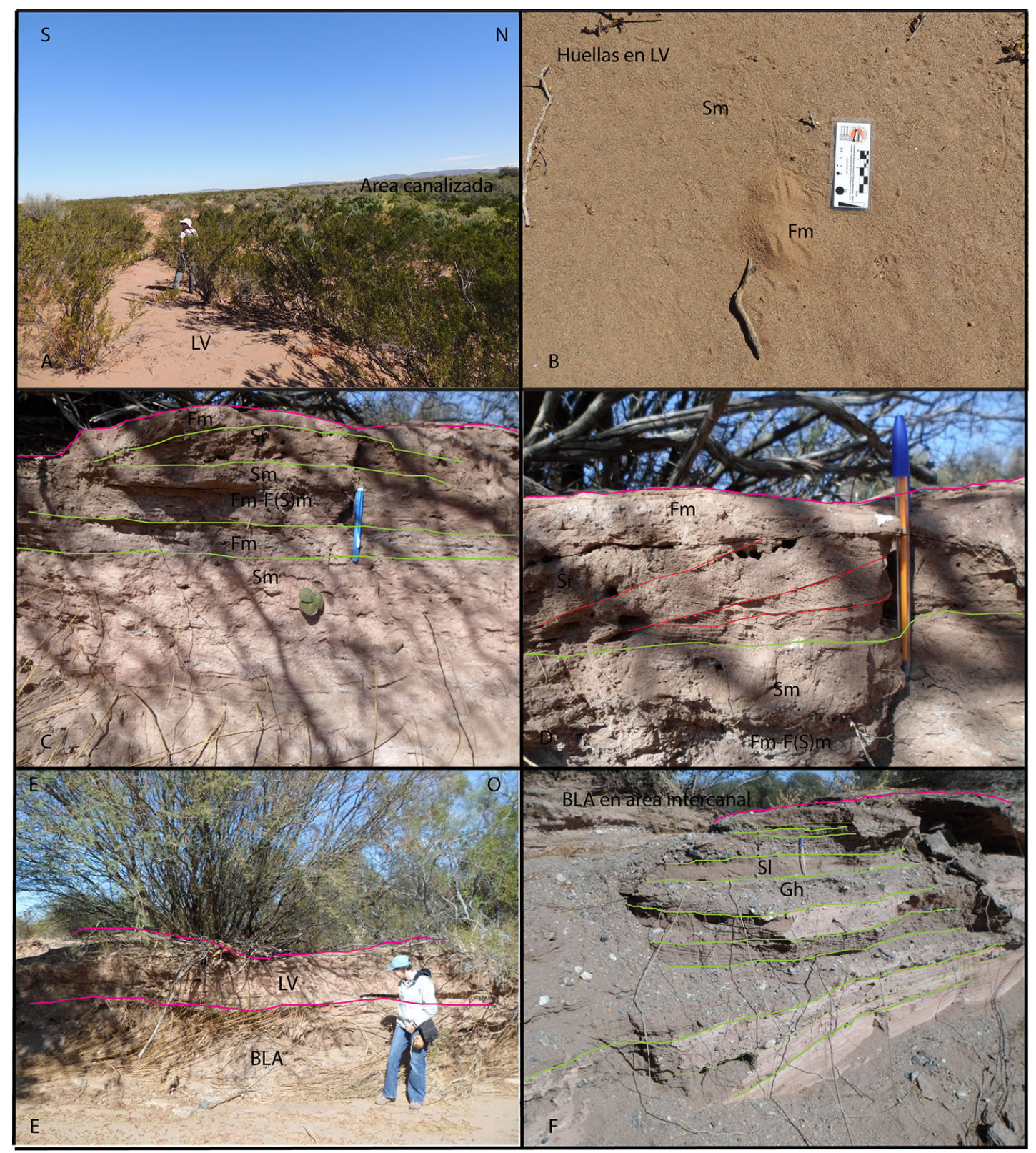

FIG. 9. Elementos arquitecturales de la llanura de inundación y área intercanal de la zona 2. A. Vista general de los albardones (LV); B. Detalle de huellas y litologías de los albardones; C-D. Detalle de litofacies de los albardones; E-F. Vista general de las áreas de intercanal y detalle de litofacies que los componen. La ubicación espacial de los elementos y su morfología en planta pueden observarse en la figura 5. La descripción de las litofacies mencionadas en la figura se encuentra en la tabla 1. LV: albardón, BLA: barra longitudinal arenosa.

por canales secundarios sinuosos que desaguan en la salina. Las litofacies definidas en este sector son Sh, Shm, Flw, Fl y Ev (Tabla 1) formando diferentes elementos arquitecturales como dunas (D, Fig. 13a, b), interduna húmeda (ID, Fig. 13c, d), y laguna de fangos salinos (SP, Fig. 13e, f). Los procesos sedimentarios dominantes son la acreción vertical de facies muy finas, generación de óndulas de oscilación por oleaje, precipitación de sales y migración de óndulas eólicas. 




FIG. 10. Principales elementos arquitecturales de la llanura de inundación de la zona 2. A. Relación lateral entre elementos CR, $\mathrm{CS}_{(\mathrm{MF})}$ y LV; B. Detalle de litofacies en CR; C. vista general de los $\mathrm{CS}_{(\mathrm{MF})}$; D. Depósito de $\mathrm{CS}_{(\mathrm{MF})}$ con sistemas de cuevas de vertebrados; E-F. Canales por erosión retrocedente $(\mathrm{CHm})$ y litofacies que los componen. La ubicación espacial de los elementos y su morfología en planta pueden observarse en la figura 5. La descripción de las litofacies mencionadas en la figura se encuentra en la tabla 1. CR: canal de lóbulo de desbordamiento, $\mathbf{C S}_{(\mathrm{MF})}$ : lóbulo de desbordamiento, LV: albardón, CHm: canales secundarios por erosión retrocedente.

\section{Ambientes sedimentarios del arroyo Papagayos}

El arroyo Papagayos es un curso de agua efímero que discurre en dirección Oeste a Este desde un cañadón estrecho formado por las sierras de La Huerta-Imanas, hasta desaguar en las cercanías de la Salina de Mascasín, formando un sistema distributario fluvial, de acuerdo al modelo de facies de Nichols 


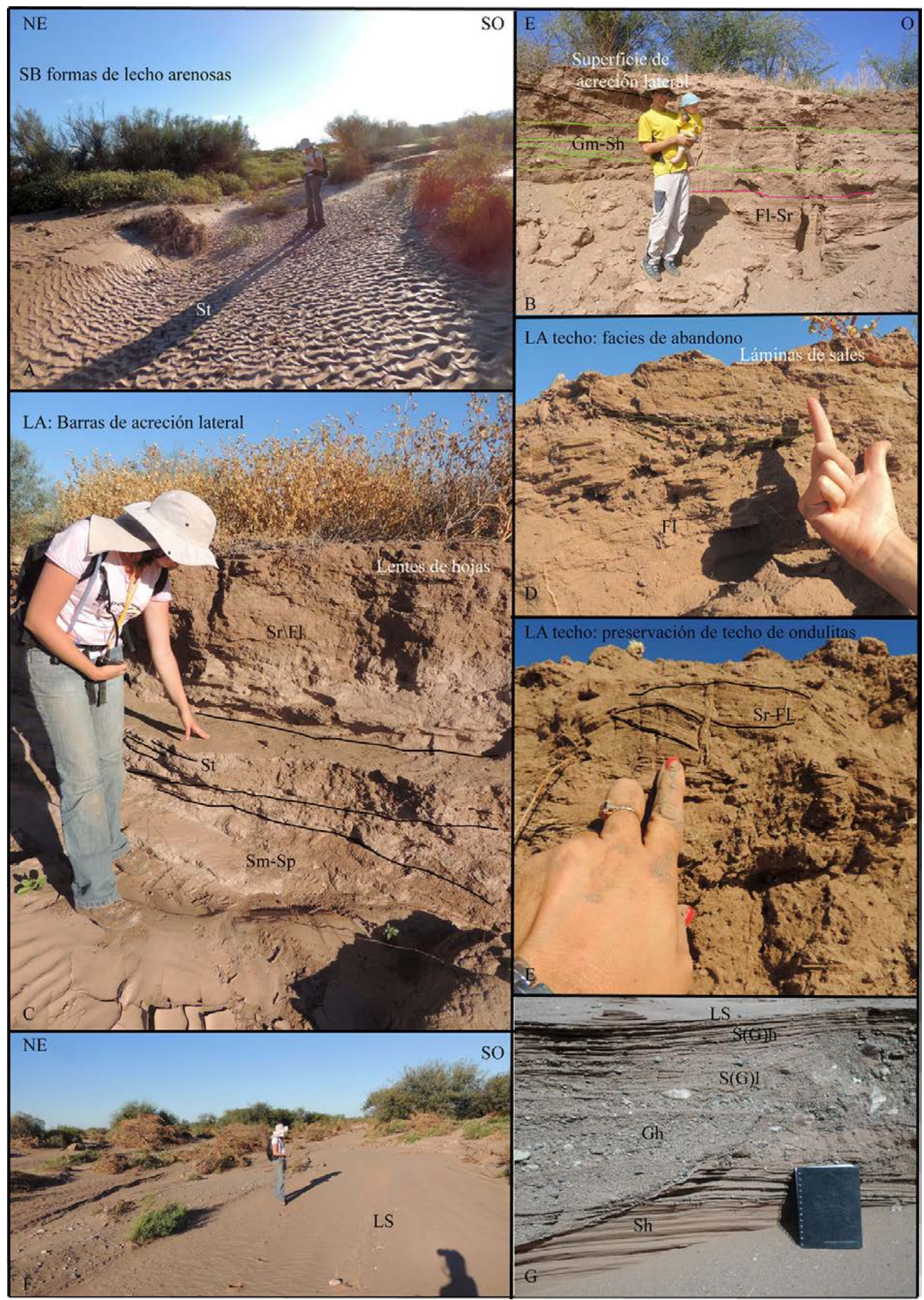

FIG. 11. Principales elementos arquitecturales de la faja de canales de la zona 3. A. Formas de lecho arenosas SB; B-C. Perfiles de las barras de acreción lateral (LA); D-E. Detalle de las litofacies del techo de las barras LA; F. Elemento mantos de arenas laminadas (LS), nótese los árboles y arbustos diseminados por el lecho fluvial; G. Perfil del elemento LS y litofacies que lo componen. La ubicación espacial de los elementos y su morfología en planta pueden observarse en la figura 5. La descripción de las litofacies mencionadas en la figura se encuentra en la tabla 1. 


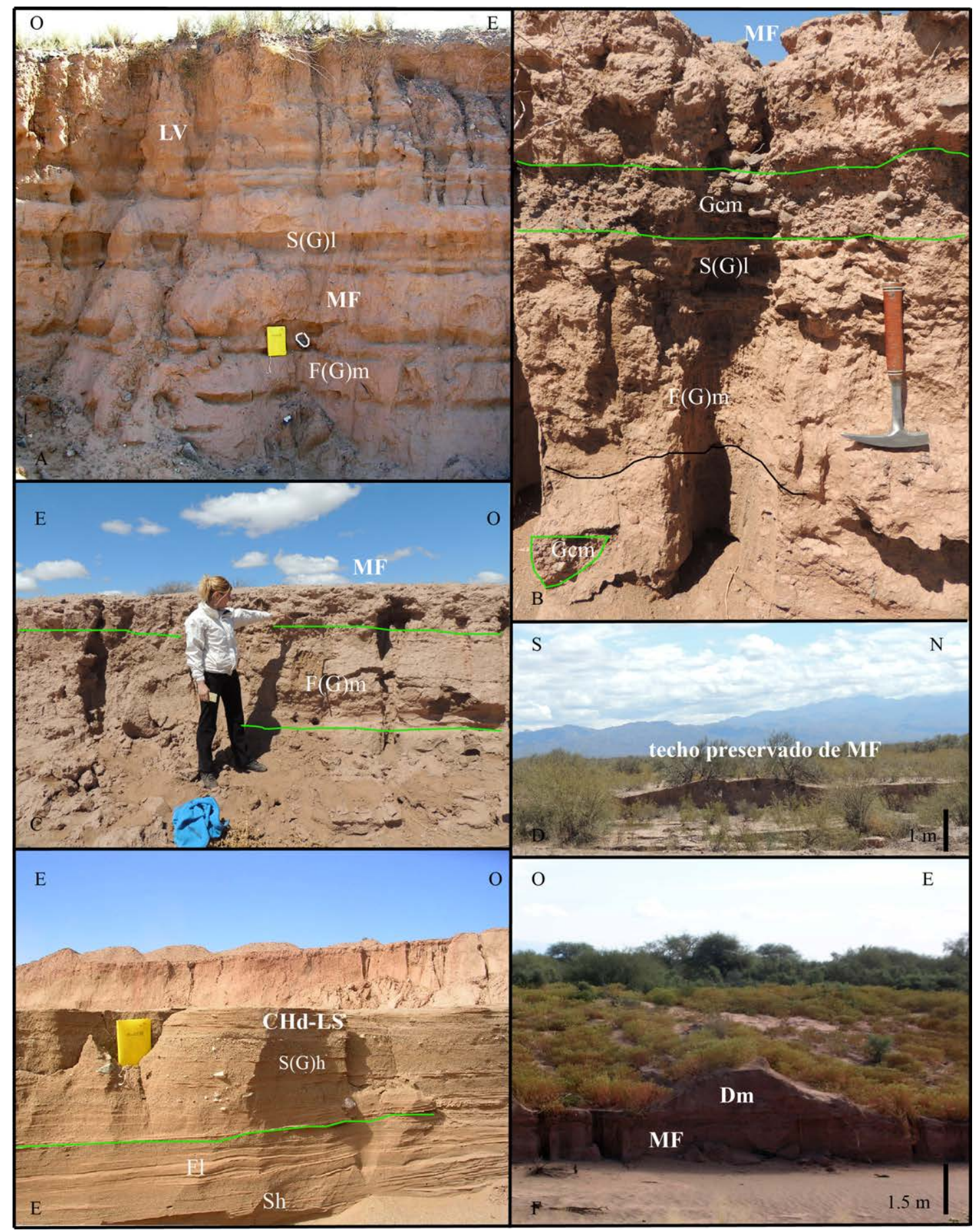

FIG. 12. Principales elementos arquitecturales de la llanura de inundación de la zona 3. A. Albardones (LV); B-C. Perfil y vista general de lóbulos terminales (MF), nótese el arreglo granocreciente; D. Morfología convexa del techo de los lóbulos terminales; E. Canales secundarios que irrigan la llanura de inundación (CHd-LS); F. Dunas menores (Dm) y su relación espacial con otros elementos (MF). La ubicación espacial de los elementos y su morfología en planta pueden observarse en la figura 5. La descripción de las litofacies mencionadas en la figura se encuentra en la tabla 1. 


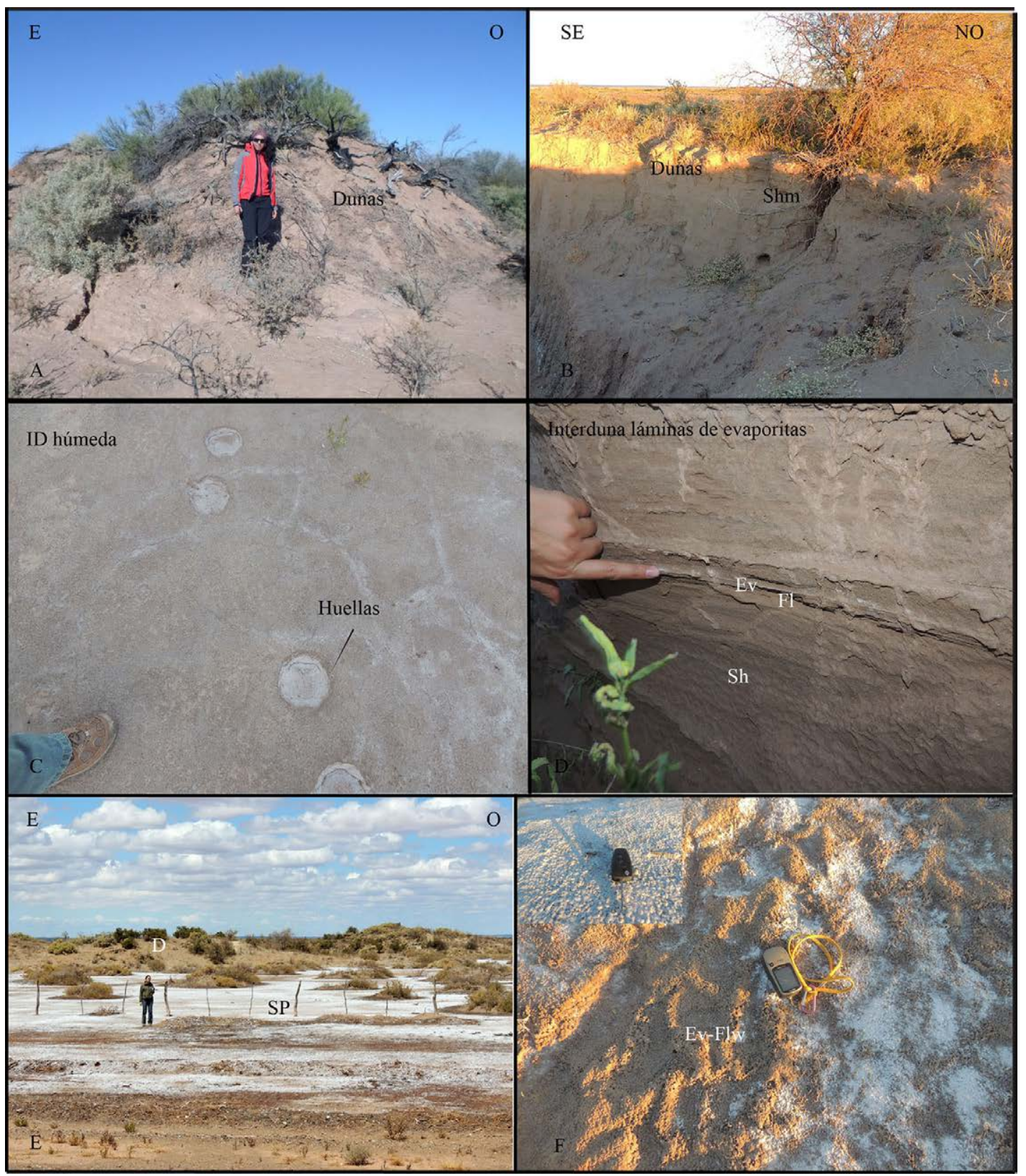

FIG. 13. Principales elementos arquitecturales de la zona 4. A. vista general de las dunas (D); B. Perfil de dunas (D); C. Elemento interduna húmeda (ID) donde se observan huellas preservadas; D. Perfil del elemento interduna (ID); E. Vista general de los elementos dunas (D) y lagunas de fangos salinos (SP); F. Detalle de litofacies en lagunas de fangos salinos. La ubicación espacial de los elementos y su morfología en planta pueden observarse en la figura 5. La descripción de las litofacies mencionadas en la figura se encuentra en la tabla 1.

y Fisher (2007). En el área del SFD del arroyo Papagayos se distinguen una serie de elementos arquitecturales que presentan un determinado arreglo de facies en función de su posición con respecto al frente montañoso, generando una sucesión de ambientes sedimentarios diferenciados de acuerdo principalmente a los cambios de pendiente en el piedemonte. 
De acuerdo con el procesamiento de las imágenes satelitales y al mapeo sedimentológico y geomorfológico de detalle realizado, se han distinguido cuatro zonas, las que presentan la asociación de diferentes elementos arquitecturales (Tabla 3 ).

La zona 1 está caracterizada por el predominio de las litofacies gravosas y arenosas, que forman los siguientes elementos arquitecturales: formas de lecho gravo-arenosas (SGB-LS), barras longitudinales (GB); barras longitudinales vegetadas (DA); barras alternas gravosas (BAG) y hoyos (HO). La combinación de estos elementos ha llevado a interpretar que la zona 1 se caracteriza por estar formada por un sistema fluvial entrelazado de carga gravo-arenosa con desarrollo de barras longitudinales altas (Miall, 1977, 1996). Se reconocen elementos de la llanura de inundación como los desbordamientos proximales (PCS), las que solo podrían ser inundadas en crecidas extraordinarias. Los desbordamientos proximales muestran un relleno sedimentario formado por litofacies gruesas (areno-gravosas). Si bien no es común la presencia de facies de llanura de inundación en el modelo de río entrelazado de Miall (1996), el desarrollo de estos depósitos en ríos entrelazados con desarrollo de barras de mayor altura, ha sido mencionado en ambientes geotectónicos similares al del arroyo Papagayos con pendientes intermedias y no las características pendientes pronunciadas de los sistemas entrelazados (cuencas sedimentarias con alta subsidencia y agradación; Miall, 1996; Jordensen y Fielding, 1996; Bristow et al., 1999). En este sistema fluvial es notable la ausencia de flujos gravitacionales no fluidos.

En la zona 2 la sinuosidad y dimensión fractal aumenta levemente, la profundización de los canales se incrementa, y se generan varios canales de menor tamaño (anchura) separados por depósitos de intercanal, favoreciendo una mayor distribución textural de los depósitos generados y mayor diversidad de elementos arquitecturales. El aumento en el número de canales se asocia a mecanismos de avulsión, vinculados a pendientes no pronunciadas, intermedias a bajas. Los distintos elementos arquitecturales se distribuyen en dos grandes áreas: un sector interno limitado por albardones de hasta $1,5 \mathrm{~m}$ de altura en donde se desarrollan las facies canalizadas y las de intercanal, y otro externo formado por las facies de llanura de inundación. Los elementos arquitecturales definidos (Tabla 3) corresponden a formas de lecho arenosas (SB), barras longitudinales vegetadas (DA) y barras longitudinales arenosas (BLA), counter point bar (CPB) y hoyos (HO). En la llanura de inundación, se observan, además, los siguientes elementos arquitecturales: albardones (LV), sistemas de canales entrelazados embrionarios (CEE), canal de lóbulo de desbordamiento (CR), lóbulos de desbordamiento con flujos de barro $\left(\mathrm{CS}_{\mathrm{MF}}\right)$ y canales secundarios $(\mathrm{CHm})$. El ambiente sedimentario interpretado para este sector es un sistema fluvial de mediana sinuosidad de carga arenosa y secundariamente gravosa. Sistemas fluviales de este tipo han sido descritos por Makaske (2001) como anastomosados con transiciones a un anabranching divagante gravoso por la presencia (aunque secundaria) de barras CPB (Nanson y Knighton, 1996). Como puede observarse se destaca en esta zona el dominio de depósitos de desbordamiento de la llanura. Estos depósitos presentan la interacción de flujos fluidos con flujos gravitacionales no fluidos de sedimentos (flujos de barro, $\mathrm{CS}_{\mathrm{MF}}$ y LV). Cabe destacar que los flujos de barro se generan en forma secundaria debido a la infiltración y concentración de sedimentos de los desbordamientos y por ello caracterizan exclusivamente la llanura de inundación (Colombi et al., 2015a).

La zona 3 se desarrolla en un área mayor dentro del piedemonte, con un ancho de hasta $6,5 \mathrm{~km}$, y forma un cono de depósitos hasta el borde de la salina. En esta zona el número de canales aumenta notablemente, aunque en algunos casos pierden conectividad con las cabeceras y vuelven a reaparecer después de ser infiltrados, posiblemente por trampas o zonas más impermeables. Las facies de canal se "simplifican", los ríos pasan de multicanalizados a monocanalizados y la sinuosidad también aumenta notablemente. La llanura de inundación se hace cada vez más importante, dejando los cursos de agua aislados dentro de los depósitos finos. Observando desde la zona 1 a la 3 , se produce una progresiva pérdida de capacidad y competencia de los cursos fluviales manifestada por la disminución de la textura de los depósitos. En la zona 3 aparecen sales y arenas eólicas por la acción depositacional del viento que empieza a cobrar importancia en esta zona para hacerse dominantes en la zona 4. Los depósitos de este sector corresponden a los siguientes elementos arquitecturales: barras de acreción lateral (LA), mantos de arenas laminadas (LS), formas de lecho arenosas (SB), hoyos (HO) y en las llanuras: albardones (LV), lóbulos de desbordamiento $\left(\mathrm{CS}_{(\mathrm{MF})}\right)$, lóbulos de desbordamiento terminal (MF), canales 
Facies proximales: aquí se depositan los sedimentos más gruesos en los canales más profundos del sistema, con características de

- Sistemas fluviales entrelazados de carga gravosa-

ह finosdellana generan fajas de canales amalgamados indicando gran movilidad lateral de los canales. Esto genera depósitos sedimentarios con gran conectivida (permeabilidad) y extensión lateral.

Facies medias: está dada por el aumento en la proporción de facies de llanura de inundación y la disminución del tamaño de los clastos que rellenan son incisas en las facies de llanura y representarían

canales de carga de lecho lateralmente móviles. Estazona pres in tación fangosi con llanura de inundación fangosa e intercalados niveles mantiformes y tabulares de arenas. Puede haber desarrollo de suelo.

Esta zona alcanza entre el 10 y el $60 \%$ de la distancia total del SFD, medida aguas abajo desde el ápice. En esta región la carga es más gruesa que en las zonas aguas abajo debido a su cercanía al área de aporte. Desarrolla gradientes pronunciados que permiten transportar sedimentos gruesos. En climas estacionales áridos es más notorio el desarrollo de pendientes más altas debido a la alta variabilidad de as descarga de sedimentos. Es común el desarrollo de fajas de canales amalgamados.

La zona 2 es la región media del SFD y se extiende entre un 35 a un $80 \%$ de la distancia total del SFD, medida aguas abajo del ápice. Se produce un marcada disminución del ancho del cauce principa en dirección aguas abajo en comparación con la zona proximal. Se produce un mayor estrechamiento de los canales. La relación canal:1lanura disminuye e la medida en que el área de inundación aumenta y se incrementa el potencial de preservación de llanura de inundación.

Facies Distales: hay una gran proporción de facies de llanura de inundación en comparación a las facies de canal. Un rasgo prominente es la mayo presencia de tablas de arenas en manto, que de 3 facies canalizadas. Estas arenas se presentan en Ẽ paquetes de gran extensión lateral, intercalados con espesos paquetes limosos y arcillosos donde se desarrolla pedogénesis.

\section{No se reconoce}

inundadas como charcas y humedales, indicando una

capa freática más próxima a la superficie y llanuras de inundación pobremente drenadas, dependiendo del clima local y las condiciones del agua subterránea.

Es una extensión de la zona distal y se caracteriza po permanecer inundada por el afloramiento de la nap freática, formando pequeños canales alimentadores de la llanura.
Domina la carga de lecho mixta arenosa y gravosa

Elem. Arq.: SGB-LS, GB, DA; BAG, HO, PCS.

Litofacies dominantes: Gmm, Gcm, Sh.

Sinuosidad: baja

Sumero de canales: uno, de carácter multicanalizado.

Sistema fluvial entrelazado gravoso poco profundo.

Alto porcentaje de interconectividad de los canales.

Vegetación es escasa, aunque concentrada en las barras. Presencia de huesos

en los canales.

El ancho que ocupa esta zona en el piedemonte es reducido (de unos $500 \mathrm{~m}$ ).

Domina la carga de lecho arenosa, menormente gravosa.

Elem. Arq.: SB, DA, BLA, CPB, HO. LV, CR, CS

Litofacies dominantes: Gci, Gh, St, Sl, Sh, Sr, F(G)m, F(S)m, Flc.

Sinuosidad: mediana.

Número de canales: varios (más de dos), multicanalizados.

Sistema fluvial: anastomosado areno-gravoso (anastomosado).

Alto porcentaje de interconectividad de los canales, gran \% de EA de llanura.

Vegetación abundante concentrada en la faja de canales donde se desarrolla

vegetación arbórea y arbustiva, y en la llanura de inundación varía de valores medios a bajos. Desarrollo importante de cuevas de vertebrados en $\operatorname{los} \mathrm{CS}_{(\mathrm{MF})} \mathrm{y}$

LV. Se observan huesos en los canales, en los LV y CS

El ancho que ocupa esta zona en el piedemonte es de unos $2,2 \mathrm{~km}$.

La zona 3 se extiende entre los 55 y 100\% de la Domina la carga de lecho arenosa, y areno-fangosa.

distancia total del SFD, medida desde el ápice. Elem. Arq.: SB, LA, LS, HO, LV, CS NF, CHd-LS, Dm y P.

La capacidad de transporte del cauce principal es Litofacies dominantes: St, Sh, Sr, Fl, F(G)m

la menor, llegando la capacidad y competencia a Sinuosidad: mediana a alta.

valores mínimos. Hay mayor participación de áreas Número de canales: monocanalizado.

Sistema fuvial meandriforme con importante interacción eólica.

Baja conectividad de canales. Permeabilidad aumentaría por incremento de depósitos eólicos. La vegetación está concentrada en canales principales, secundarios y en las dunas. Desarrollo de cuevas en los $\mathrm{CS}_{(\mathrm{MF})}$ y LA. Abundante apilamiento de restos de árboles y arbustos en el lecho fluvial activo. El ancho que ocupa en el piedemonte es de $6,2 \mathrm{~km}$.

Aflora el nivel freático y se desarrollan ambientes asociados a la salina, no se considera dentro del SFD del arroyo Papagayos.

Elem. Arq.: D, ID y SP.

Litofacies dominantes:Shm, Fl, Ev,

Los ambientes desarrollados están asociados al SFD. Faja litoral de la salina dominio de acumulación eólica y llegan canales secundarios alimentados en época estival. Vegetación concentrada en las dunas. En las interdunas se preservan huellas de vertebrados, desarrollo de cuevas en dunas. Ocupa un área mucho mayor. ya que bordea el cuerpo de agua de la salina. 
secundarios de carga areno-limosa (CHd-LS), Dunas menores o protodunas $(\mathrm{Dm})$ y Charcas $(\mathrm{P})$. La característica más llamativa de esta zona es que el cauce principal desparece por la disminución de la pendiente y al desaparecer genera los lóbulos terminales (Fig. 5). La infiltración también sería un factor condicionante para la desaparición del cauce principal del arroyo Papagayos y estaría controlada por la faja de depósitos eólicos que se desarrolla al borde de la salina, generando no solo la desaparición del cauce principal por infiltración, sino la de varios cauces del piedemonte. Tanto en lóbulos terminales como en desbordamiento laterales se destaca la presencia de procesos gravitacionales no fluidos de sedimentos (flujos de barro) generados en forma secundaria. El sistema depositacional interpretado para este sector corresponde con un sistema fluvial distal de carga arenosa de alta sinuosidad y flujos en manto con importante interacción eólica (Miall, 1996; Tripaldi y Limarino, 2008). En este caso la baja pendiente favorece la alta sinuosidad de los cursos y consecuentemente el dominio de los procesos de migración lateral sobre los de avulsión y bifurcación de los canales.

La zona 4 representa una región transicional a la salina en donde se observa una cercana interacción de ambos sistemas depositacionales. Esta área es mayor que las anteriores, ya que se continúa lateralmente bordeando toda la salina. El cauce principal del SFD del arroyo Papagayos no recorre este sector, ya que desaparece por infiltración generando los lóbulos terminales en la zona 3. Los elementos arquitecturales aquí definidos tienen más relación con el ambiente de la salina que con los ambientes sedimentarios del SFD. La zona 4 representa un ambiente de muy baja energía, con principal desarrollo de áreas deprimidas inundadas donde aflora la napa freática, con desecamiento estacional (SP). Estas lagunas están rodeadas por arenas laminadas bien seleccionadas con gran cantidad de vegetación concentrada (dunas D) y surcadas por canales secundarios de carga limosa y arenosa de muy baja energía que forman las interdunas (ID). Este sector es interpretado como la faja litoral de la salina donde domina la acumulación eólica y llegan canales secundarios alimentados por las precipitaciones en forma directa o el aumento del nivel freático en época estival, generando la dominancia de mecanismos de agradación vertical (Spalletti y Colombo Piñol, 2005; Arche, 2010).

\section{Discusión}

El arroyo Papagayos presenta una red de drenaje divergente aguas abajo que desarrolla un cono de depósitos con morfología de abanico alejado del frente montañoso, en este caso a $12 \mathrm{~km}$ de distancia, aspectos que permiten identificar este sistema como un SFD (Hartley et al., 2010). Además, se suman otras características distintivas de los SFD observadas en este ambiente sedimentario como (Tabla 3): a) el dominio de flujos canalizados no viscosos a lo largo de todo el sistema, b) el reconocimiento de una zonación aguas abajo: proximal, media y distal, c) el aumento de la sinuosidad de los sistemas de canales aguas abajo, d) el aumento de número de canales aguas abajo y la disminución del tamaño de los mismos y e) la disminución de la capacidad y competencia de las corrientes tractivas (Nichols y Fisher, 2007; Weissmann et al., 2010; Hartley et al., 2010).

La caracterización del SFD del arroyo Papagayos permite la identificación de tres zonas. En la zona proximal se observa un sistema fluvial entrelazado profundo de carga de lecho tractiva, en la zona media se desarrolla un sistema fluvial anastomosadoanabranching divagante gravoso con carga de lecho mixta y finalmente en la zona distal un sistema fluvial meandriforme dominado por carga en suspensión. En su terminación este ambiente interacciona con el sistema de drenaje axial, en este caso con los depósitos eólicos de la faja costera de la salina de Mascasín, lo cual ha sido observado en otros sistemas fluviales distributivos de cuencas endorreicas y de clima árido (Hartley et al., 2010). La zona media y principalmente la distal se caracterizan, además, por la presencia de flujos producto de procesos gravitacionales de sedimentos, litofacies $\mathrm{F}(\mathrm{G}) \mathrm{m}$; sin embargo estos se observan solamente en la llanura de inundación. Otra característica de este sistema, es la desaparición del canal principal en la parte media de la zona distal, generando depósitos de cuerpos lobulados y de morfología convexa denominados lóbulos terminales que, en general, le dan una topografía positiva a todo el depósito (Nichols and Fisher, 2007; Hartley et al., 2010). Con respecto al tipo de SFD, la distribución espacial observada de los sistemas fluviales que integran el arroyo Papagayos es similar al modelo 3 de SFD "entrelazado a meandriforme", dominado por una alta descarga y bajo gradiente de acuerdo con la clasificación de Hartley et al., (2010). 
La pendiente del piedemonte en el que se inserta el SFD del arroyo Papagayos se caracteriza por ser baja (menor a $1^{\circ}$ ) y decrece desde el borde del frente montañoso hacia la cuenca (desde $0,5^{\circ}$ a $0,2^{\circ}$ ). La baja pendiente generalizada favorece: a) la presencia de lóbulos de desbordamiento en todo el desarrollo, incluso en los sistemas entrelazados donde normalmente no se generan estos subambientes (Miall, 1996), y b) la generación en la zona distal de los lóbulos terminales, los que caracterizan a estos ambientes de acuerdo al modelo propuesto por Nichols y Fisher (2007). La baja pendiente observada en el piedemonte oriental se asocia al perfil asimétrico que presenta la sierra de La Huerta y su continuación septentrional, la sierra de Valle Fértil, asociado a la presencia de la megafractura Valle Fértil en su faldeo occidental (Roselló et al., 1997; Vujovich et al., 2007; Rothis et al., 2012). Esto genera que en su ladera occidental presente una mayor pendiente, mientras que en su ladera oriental, donde se desarrolla el SFD del Papagayos, presenta un gradiente menor, generando un piedemonte con una topografía suavizada (Vujovich et al., 2007; Rothis et al., 2012). Además, la leve disminución de la velocidad de subsidencia de la cuenca donde se emplaza la Salina de Mascasín durante el Cuaternario (Azeglio et al., 2008), también favorecería un bajo gradiente en la cuenca y el desarrollo de un patrón depositacional altamente agradante característico de estos sistemas depositacionales.

Además de la pendiente, la presencia de estacionalidad climática es considerada un factor importante para el desarrollo de un SFD de acuerdo con los ejemplos modernos (Hartley et al., 2010) y del registro geológico (Nichols y Fisher, 2007). La fisiografía del paisaje de Sierras Pampeanas Occidentales donde se inserta el SFD del arroyo Papagayos permite considerar la depresión del Bajo Oriental como un desierto de sombra de montaña. Los umbrales de la cuenca de drenaje del arroyo Papagayos se desarrollan bajo un clima estacional semiárido de estepa mientras que el valle presenta un clima estacional árido. Esto significa que en la época estival la cuenca de drenaje recibe mayores precipitaciones que la región del valle. Además, la red de drenaje de la cuenca del arroyo Papagayos es densa y se desarrolla sobre materiales impermeables y fácilmente erosionables, que en la época estival favorecen el escurrimiento superficial rápido que es inmediatamente encauzado en el cañadón fuente del arroyo (Rothis et al., 2015). Al llegar al valle la evaporación generada por un clima más árido e infiltración producto de un sustrato permeable, favorecen la desaparición del canal principal generando lóbulos terminales en la porción media de la zona distal. En conjunto, las condiciones climáticas áridas del valle y semiáridas de las sierras, y las características mencionadas de la cuenca de drenaje regularían una descarga alta y una tasa de sedimentos moderada que, sumados al bajo gradiente, favorecen el desarrollo de un patrón depositacional agradante, característico de estos sistemas (Nichols y Fisher, 2007) y la formación del SFD.

Hay varios factores observados en los depósitos del arroyo Papagayos que lo diferencian del modelo sedimentario de los abanicos aluviales (Tabla 4). La pendiente observada en el arroyo Papagayos es baja a muy baja mientras que en los abanicos aluviales se reportan valores de $1,5^{\circ}$ a $25^{\circ}$; siendo entre $5^{\circ}$ y $10^{\circ}$ en la cabecera (Blair y Macpherson, 1994; Miliaresis y Argialas, 2000; Colombo, 2010; Hartley et al., 2010). Esto gobierna que en un abanico aluvial el diseño planimétrico en abanico y divergencia del drenaje, se produzcan en el borde del frente montañoso de donde el río que lo alimenta emerge, disparado por la pérdida del confinamiento y la mayor pendiente del piedemonte (Blair y Macpherson, 1994). Consecuentemente, los procesos sedimentarios que los caracterizan son diferentes a los observados en los SFD, a pesar de que en los abanicos aluviales también se reconocen tres zonas aguas abajo. Los procesos sedimentarios dominantes en los abanicos aluviales se caracterizan en la zona cabecera o apical por el dominio de procesos gravitacionales de rocas y sedimentos que generan flujos no confinados, flujos de detritos gruesos, flujos detritos secos, avalanchas de roca y/o flujos de detritos arenosos; en la zona del cuerpo del abanico dominan los flujos acuosos y en la zona del pie del abanico se caracterizan por el dominio de flujos no confinados de carga en suspensión (Colombo, 2010). En cambio, la menor pendiente de los SFD y, del caso de estudio, provoca que dominen los procesos sedimentarios no viscosos canalizados en sus tres zonas, sin presentarse procesos gravitacionales de rocas, salvo en la zona media y principalmente la distal donde aparecen flujos de barro densos $(\mathrm{F}(\mathrm{G}) \mathrm{m})$, restringidos a la llanura de inundación. La generación de estos flujos de barro es interpretada como secundaria, asociada a la infiltración y densificación de la matriz de flujos desbordados (Shultz, 1984; Colombi et al., 2015a). 


\section{TABLA 4. DIFERENCIAS ENTRE EL MODELO DE ABANICO ALUVIAL CLÁSICO Y LOS SISTEMAS FLUVIALES} DISTRIBUTIVOS (SFD).

\begin{tabular}{llllll}
\hline \multicolumn{1}{c}{ Ambiente } & \multicolumn{1}{c}{ Ubicación } & Pendiente & Morfología & $\begin{array}{l}\text { Tipo de canales y } \\
\text { Sedimentos Dominantes }\end{array}$ & $\begin{array}{l}\text { Dinámica de } \\
\text { Transporte }\end{array}$ \\
\hline Abanicos aluviales & $\begin{array}{l}\text { Sobre el frente } \\
\text { montañoso. }\end{array}$ & $\begin{array}{l}\text { Moderada } \\
\text { hasta alta } \\
\text { pendiente } \\
\text { (por lo general } \\
\left.\text { entre } 1^{\circ} \mathrm{y} 3^{\circ}\right) .\end{array}$ & $\begin{array}{l}\text { Por lo general, } \\
\text { abanicos } \\
\text { simétricos, con } \\
\text { radio de abanico } \\
\text { menor a } 1 \mathrm{~km} .\end{array}$ & $\begin{array}{l}\text { Dominan canales de baja } \\
\text { slujuosidad con relleno } \\
\text { gravo-arenoso a areno- } \\
\text { gravoso. }\end{array}$ & $\begin{array}{l}\text { y fluidos. Los } \\
\text { primeros frecuentes } \\
\text { en el abanico } \\
\text { proximal. }\end{array}$ \\
$\begin{array}{l}\text { Sistemas Fluviales } \\
\text { Distributivos* }\end{array}$ & $\begin{array}{l}\text { Se desarrollan a } \\
\text { varios kilómetros } \\
\text { del frente de } \\
\text { montaña. }\end{array}$ & $\begin{array}{l}\text { Baja a muy } \\
\text { baja pendiente } \\
\left(\text { menor a } 1^{\circ}\right) .\end{array}$ & $\begin{array}{l}\text { Formas elongadas } \\
\text { con radio de } \\
\text { abanico de varios } \\
\text { kilómetros. }\end{array}$ & $\begin{array}{l}\text { Variable sinuosidad de } \\
\text { canales, desde baja a } \\
\text { alta con rellenos areno- } \\
\text { fangoso. }\end{array}$ & $\begin{array}{l}\text { Flujos fluidos, de } \\
\text { existir flujos densos, } \\
\text { frecuentes en el } \\
\text { abanico distal. }\end{array}$ \\
\hline
\end{tabular}

${ }^{*}$ En sentido amplio, incluye abanicos terminales y megaabanicos.

También hay varios factores que permiten distinguir al SFD del arroyo Papagayos, de un clásico sistema fluvial. Los SFD se diferencian de los sistemas fluviales en el patrón distributario versus tributario, ya que los SFD raramente presentan tributarios a lo largo de su recorrido, lo que lleva a una disminución en el tamaño de los canales aguas abajo, como se observa en el SFD del Papagayos (de $160 \mathrm{~m}$ a $10 \mathrm{~m}$ de ancho). Por su parte, en los sistemas fluviales, hay un incremento del tamaño de los canales aguas abajo en la medida en que los cauces tributarios contribuyen al mismo. Otros aspectos importantes observados son la determinación clara de tres zonas en los SFD; la presencia de procesos gravitacionales de sedimentos secundarios en las llanuras de inundación; la presencia de lóbulos terminales en la zona distal y en general su posición en la cuenca. Los SFD en su mayoría se ubican como sistemas de drenaje transversales y los sistemas fluviales como sistemas axiales, aunque se han reportado algunos SFD de gran dimensión axiales (SFD del río Bermejo en el norte Argentino que excede los $700 \mathrm{~km}$ de extensión; Hartley et al., 2010).

Sobre la base de la distinción de estos ambientes de los abanicos aluviales y de los grandes sistemas fluviales, el reconocimiento de estos sistemas en el registro geológico resulta más claro y la caracterización de los mismos podría resumirse como: 1) la presencia de tres zonas, cada una caracterizada por sistemas fluviales de baja y alta sinuosidad altamente agradantes cada uno de su tipo. Zona proximal: entrelazado con desarrollo de facies de llanura de inundación gruesa (Gcm, Sm, Sh, Flc; Gmm-Gcm,
Sh, Sl; Gci, Bci; Gci, S(G)m, S(G)h); zona media: sistema fluvial de mediana sinuosidad (Gcm, Sp, St, $\mathrm{Sr}, \mathrm{Flc}$; Gcm, Gh, S(G)m, Sl, St) caracterizado por llanuras de inundación dominadas por lóbulos de desbordamiento (S(G)m, Sm, Fm, F(S)m, F(G)m, Sr; $\mathrm{F}(\mathrm{S}) \mathrm{l}, \mathrm{F}(\mathrm{S}) \mathrm{m}, \mathrm{F}(\mathrm{G}) \mathrm{m}, \mathrm{S}(\mathrm{G}) \mathrm{m})$, zona distal: sistemas de alta sinuosidad ( $\mathrm{Sm}, \mathrm{Sp}, \mathrm{St}, \mathrm{Ar}, \mathrm{Fl}$; Gmm, S(G)l, $\mathrm{Sh}, \mathrm{Sr}, \mathrm{Fl})$ ) con llanuras caracterizadas por acreción de lóbulos de desbordamiento y lóbulos terminales (F(G)m, S(G)m, Gmm; F(G)m, S(G)1, Gcm, Ev); 2) un rápido pasaje vertical de una zona a otra o de un sistema fluvial a otro, manifestando la concatenación aguas abajo de los diferentes sistemas fluviales que caracterizan cada zona, finalizando en la porción distal en facies eólicas junto con facies de barreal o salinas y, en general, con un patrón depositacional progradante; 3) aumento de la sinuosidad, disminución de tamaño de los canales y aumento de número de canales aguas abajo; 4) el dominio de procesos sedimentarios de flujos acuosos en los canales, mientras que en la llanura de inundación presentan una importante participación de flujos de barro $(\mathrm{F}(\mathrm{G}) \mathrm{m})$; 5) la presencia de lóbulos terminales en la zona distal caracterizados por la presencia de litofacies más gruesas que un lóbulo de desbordamiento de la llanura de inundación, ausencia de canalización y superficies convexas en su techo $(\mathrm{F}(\mathrm{G}) \mathrm{m}, \mathrm{S}(\mathrm{G}) \mathrm{l}$, $\mathrm{Gcm}, \mathrm{Ev}) ; 6$ ) una restringida continuidad lateral ya que se observa que su distribución es muy reducida dentro del piedemonte, siendo en la zona proximal de $200 \mathrm{~m}$ y unos $6 \mathrm{~km}$ en la zona distal, por lo que es esperable encontrar facies sedimentarias de piedemonte relacionados vertical y lateralmente con los SFD. 
En la región bajo estudio se han reconocido SFD para el Triásico-Jurásico identificados por: a) la concatenación de sistemas fluviales de baja a alta sinuosidad, b) dominio de flujos no viscosos a lo largo del sistema, c) presencia de fajas de paleocanales cuyos depósitos de llanura de inundación están caracterizados por flujos de barro y d) la interacción con facies de barreal o salina (véase Colombi et al., 2015a; Colombi et al., 2015b). Cabe destacar que comparando los SFD mesozoicos y el ejemplo bajo estudio, es llamativa su ubicación en sentido Oeste-Este. Tal disposición coincidiría con grandes lineamientos Oeste-Este, que actualmente atraviesan el orógeno andino y el antepaís fracturado, estructuras que ejercerían un control estructural en la red de drenaje y en el desarrollo de estos sistemas depositacionales (Japas et al., 2008; Castro de Machuca et al., 2013; Castro de Machuca y Perucca, 2015; Jofré, 2015).

La presencia de los depósitos de megaabanicos, y en sentido amplio de SFD, es frecuente en cuencas de antepaís evolucionadas y vinculadas a grandes áreas orogénicas como los Andes e Himalayas (véase por ejemplo Gupta, 1997; DeCelles y Cavazza, 1999; Horton y DeCelles, 2001). De hecho, gran parte de las acumulaciones de megaabanicos descritas en ambientes antiguos y actuales, corresponde a la parte central y austral de la Cordillera de los Andes, como por ejemplo los megaabanicos de los ríos Grande, Parapetí, Pilcomayo, Bermejo, Huaco y Jachal, entre otros (Damanti, 1993; Iriondo et al., 2000; Horton y DeCelles, 2001; Suvires, 2014; McGlue, 2016).

Tal como lo señalaran Horton y DeCelles (2001), el desarrollo de megaabanicos se encuentra favorecido por la presencia de una faja de cabalgamientos extensa y con una red de drenaje bien integrada, la que culmina en el frente orogénico en unos pocos sistemas fluviales capaces de transferir grandes volúmenes de sedimentos desde las cuencas intramontanas al área de antepaís. Este diseño fue previamente destacado en los Himalaya por Gupta (1997), al señalar que el patrón de drenaje, al que llamó gridiron geometry, era crítico para el desarrollo de megaabanicos en la cuenca del Ganges. En ocasiones, las acumulaciones de SFD y megaabanicos se inician en el mismo frente orogénico conformando los llamados "abanicos de by pass" localizados en el sector de tope de cuña (Tedesco et al., 2013).

La formación de fajas de cabalgamientos extensas, cuencas intramontanas bien desarrolladas y sistemas fluviales que drenan transversalmente al orógeno transfiriendo los sedimentos hacia el antepaís, se han establecido en la Cordillera de los Andes al menos desde el Mioceno. Si bien la identificación de depósitos de megaabanicos, en unidades neógenas pertenecientes a la orogenia andina, se ha incrementado en la última década (véase por ejemplo Horton y DeCelles, 2001; Mosolf et al., 2010; DeCelles et al., 2011; Hain et al, 2011; Suriano et al., 2015), una de las mayores dificultades para su reconocimiento es el número relativamente bajo de análogos actuales que permita mejorar su caracterización. Los resultados obtenidos en el presente trabajo muestran que para el reconocimiento de estos ambientes sedimentarios en secuencias antiguas, son críticos tres factores: 1. Establecer y vincular en un único modelo las variaciones laterales de facies, 2. Analizar adecuadamente la arquitectura depositacional de cada uno de los subambientes y 3. Estudiar en detalle no solo los depósitos de canal, sino también las características de las planicies de inundación, las que por su extensión forman una parte sustancial de los SFD y de los megaabanicos.

Por último, considerando los SFD como potenciales reservorios, sobre la base de la distribución de los materiales a lo largo del SFD del arroyo Papagayos, se observa que el mismo presentaría un potencial similar al propuesto por Nichols y Fisher (2007), por lo que, el potencial de interconectividad entre cuerpos arenosos de los canales disminuiría a medida que divergen y quedan inmersos en depósitos fangosos de la llanura de inundación. Aunque, a diferencia de lo propuesto por Nichols y Fisher (2007), en la zona distal y en la terminación del SFD bajo estudio la interacción eólica con las facies de llanura de inundación es importante, por lo que favorecería en este caso la conectividad entre facies de canal.

\section{Conclusiones}

En el piedemonte oriental de las sierras de La Huerta-Imanas emerge el arroyo efímero Papagayos desde un estrecho cañadón hacia la cuenca endorreica de la salina de Mascasín. A lo largo del piedemonte y hasta el límite entre el piedemonte y la salina este arroyo genera diferentes depósitos que han sido clasificados de acuerdo a sus características sedimentológicas como un Sistema Distributario Fluvial o un Sistema Fluvial Distributivo (Nichols y Fisher, 2007; Weissmann et al., 2010; Davidson et al., 2013). En este sistema se han reconocido tres zonas y se han caracterizado en cada una de ellas 
las litofacies y elementos arquitecturales presentes a fin de colaborar en su reconocimiento en el registro sedimentario antiguo, lo cual está subdesarrollado en la literatura existente. De acuerdo con su distancia al ápice las zonas se han denominado proximal, media, distal, todas con valores de pendiente muy bajos menores a $1^{\circ}$. La cuarta zona (transicional con la salina) no se considera dentro del modelo del SFD del arroyo Papagayos ya que los procesos sedimentarios que allí ocurren están íntimamente relacionados con el ambiente de la salina. Las tres zonas reconocidas dentro del SFD están dominadas por procesos sedimentarios de flujos acuosos, y en las facies de llanura de inundación también se observan procesos de flujos gravitatorios de sedimentos. La morfología del depósito y las características sedimentológicas en cada zona muestran una disminución aguas abajo de la capacidad y competencia de los canales, pasando de un sistema fluvial entrelazado gravo-arenoso profundo, a un sistema fluvial anastomosado-anabranching divagante areno-gravoso y finalmente un sistema fluvial distal de alta sinuosidad carga arenosa con interacción eólica.

El SFD del arroyo Papagayos presenta tres zonas las cuales se caracterizan por:

Zona proximal. Litofacies dominantes gravosas y arenosas gruesas, menormente fangosas en los elementos arquitecturales: formas de lecho gravoarenosas (SGB-LS), barras longitudinales (GB); barras longitudinales vegetadas (DA); barras alternas gravosas (BAG) y hoyos (HO), y en la llanura de inundación desbordamientos proximales (PCS).

Zona media. Litofacies dominantes arenosas, fangosas y gravosas, en los elementos arquitecturales: formas de lecho arenosas (SB), barras longitudinales vegetadas (DA) y barras longitudinales arenosas (BLA), counter point bar (CPB), hoyos (HO). En la llanura de inundación, se observan Albardones (LV), Sistemas de canales entrelazados embrionarios (CEE), Canal de lóbulo de desbordamiento (CR) y canales secundarios $(\mathrm{CHm})$, un elemento característico de este sistema son los Lóbulos de desbordamiento con flujos de barro $\left(\mathrm{CS}_{\mathrm{MF}}\right)$ con litofacies fango-gravillosas.

Zona distal. Litofacies dominantes arenosas y fangosas, menormente gravosas en los elementos arquitecturales: barras de acreción lateral (LA), mantos de arenas laminadas (LS), formas de lecho arenosas (SB), hoyos (HO). Las llanuras de inundación presentan: albardones (LV), Lóbulos de desbordamiento $\left(\mathrm{CS}_{(\mathrm{MF})}\right)$, lóbulos de desbordamiento terminal (MF), los que presentan litofacies fangogravillosas, canales secundarios de carga areno-limosa (CHd-LS) y charcas (P). También se observan facies eólicas como dunas menores o protodunas (Dm).

El marco geológico, en el antepaís andino fracturado, donde se emplaza este SFD, sumado al clima estacional árido genera condiciones favorables para el desarrollo de este sistema. La acomodación producida por la subsidencia de la cuenca mantiene un bajo gradiente de la pendiente en los sistemas fluviales, permitiendo el desarrollo de sistemas depositacionales altamente agradantes. Ésto, sumada al perfil asimétrico que presentan la serranía de Valle Fértil-La Huerta-Las Imanas, genera una baja pendiente en su piedemonte oriental y fomenta la continua avulsión de los canales y el desarrollo de un patrón depositacional distributario y agradante desarrollado lejos del frente montañoso. Por otro lado, las precipitaciones estacionales, torrenciales, con mayor humedad en la sierra que en el valle, y la impermeabilidad y alta erosionabilidad de las rocas en donde se encuentra la cuenca de drenaje, favorecen una tasa de agua moderada, llevadas a través de crecientes concentradas en la estación estival.

Finalmente, la importante interacción eólica desarrollada en la llanura de inundación en la porción distal del SFD favorecería la interconectividad entre cuerpos de canal, a diferencia del modelo general propuesto (Nichols y Fisher, 2007) para evaluar el potencial como reservorio de estos sistemas. Este factor se debería tener en cuenta cuando se analicen en el registro depósitos de este tipo desarrollados en climas áridos, donde esta interacción es tan común.

\section{Agradecimientos}

Los autores agradecen a los evaluadores y al Editor Sr. W. Vivallo, cuyas observaciones, comentarios y sugerencias permitieron mejorar la calidad integral de este trabajo. También agradecemos al Instituto y Museo de Ciencias Naturales, FCEFyN-UNSJ por su apoyo financiero. Este trabajo fue parcialmente financiado por el proyecto PICT 2015-2074 (CC) otorgado por la Foncyt.

\section{Referencias}

Allen, J. 1983. Studies in fluviatile sedimentation: bars, bar-complexes and sandstone sheets (low-sinuosity braided streams) in the Brownstones (L. Devonian), Welsh Borders. Sedimentary Geology 33: 237-293. 
Anderson, R.S. 1987. A theoretical model for aeolian impact ripples. Sedimentology 34 (5): 943-956.

Arche Miralles, A. 2010. Sedimentología: Del proceso físico a la cuenca sedimentaria. Consejo Superior de Investigaciones Científicas: 1290 p. Madrid.

Armas, P.; Sánchez, M.L. 2013. Sedimentología y arquitectura de las dunas costeras de la Formación Allen, Grupo Malargüe, cuenca Neuquina-Río Negro, Argentina. Revista Mexicana de Ciencias Geológicas 30 (1): 65-79.

Ashley, G.M. 1990. Classification of large-scale subaqueous bedforms: a new look at an old problem. Journal of Sedimentary Petrology 60 (1): 160-172.

Ashmore, P.E. 1991. How do gravel-bed rivers braid? Canadian Journal of Earth Science 28: 326-341.

Azeglio, E.A.; Giménez, M.E.; Introcaso, A. 2008. Análisis de subsidencia de la Cuenca de Las Salinas, Sierras Pampeanas Occidentales. Revista de la Asociación Geológica Argentina 63 (2): 272-280.

Azeglio, E.A.; Giménez, M.E.; Introcaso, A. 2010. Interpretation of Las Salinas sedimentary basin-Argentina, based on integration of geological and geophysical data. Geofísica Internacional 49 (4): 225-244.

Bagnold, R.A. 1954. Experiments on a gravity-free dispersion of large solid spheres in a Newtonian fluid under shear. In Proceedings of the Royal Society of London A: Mathematical, Physical and Engineering Sciences 225 (1160): 49-63.

Blair, T.; Mcpherson, J. 1994. Alluvial fans and their natural distinction from rivers based on morphology, hydraulic processes, sedimentary processes, and facies assemblages. Journal of Sedimentary Research (A64): 450-489.

Bossi, G.; Villanueva García, A.; Godeas, M.; Kousal, M. I.; Lutz, M.A.; Monteros, C. 1975. Análisis estadístico de imbricaciones en la Formación Quebrada del Barro, Marayes, Prov. de San Juan, Argentina. Revista de la Asociación de Mineralogía, Petrología y Sedimentología 6 (1-2): 23-54.

Bossi, G. 1976. Geología de la Cuenca de Marayes-El Carrizal (Provincia de San Juan), República Argentina. In Congreso Geológico Argentino, No. 6, Actas: 2338. Bahía Blanca.

Bristow, C.S.; Skelly, R.L.; Ethridge, F.G. 1999. Crevasse splays from the rapidly aggrading, sand-bed, braided Niobrara River, Nebraska: effect of base-level rise. Sedimentology 46: 1029-1047.

Bruniard, E.D. 1982. La diagonal árida Argentina: un límite climático real. Revista Geográfica (95): 5-20.
Carrasco Pereira, P.F.; Arce, E.C.; Rudorff, B.F.T.; Moreira, J.C. 2005. Aplicaciones agrícolas y forestales de las bandas 3 y 4 del sensor CCD en combinación con la banda 2 del sensor IR-MSS del satélite CBERS. In Simpósio Brasileiro de Sensoriamento Remoto, No. 12, Anais 857-864. Goiânia.

Carvacho Bart, L.; Sánchez Martínez, M. 2010. Comparación de índices de vegetación a partir de imágenes MODIS en la Región del Libertador Bernardo O’Higgins, Chile, en el período 2001-2005. In Tecnologías de la Información Geográfica: La Información Geográfica al servicio de los ciudadanos (Ojeda, J.; Pita, M.; Vallejo, I.; editores). Secretariado de Publicaciones de la Universidad de Sevilla: 728-737. Sevilla.

Castro de Machuca, B.C.; Perucca, L.P. 2015. Fault-related carbonate breccia dykes in the La Chilca area, Eastern Precordillera, San Juan, Argentina. Journal of South American Earth Sciences 58: 100-110.

Castro de Machuca, B.; Perucca, L.; Conte-Grand, A.; Pontoriero, S.; Meiss1, E.; Martos, L. 2013. Edad y geoquímica del magmatismo traquítico de Precordillera Oriental, provincia de San Juan. In Simposio sobre Petrología Ignea y Metalogénesis Asociada, No. 2, Resúmenes: 16-17. San Luis.

Colombi, C.E.; Martínez, R.N.; Correa, G.A.; Fernández, E.; Santi Malnis, P.; Praderio, A.; Apaldetti, C.; Abelín, D.; Alcober, O.; Aguilar-Cameo, A. 2015a. First Argentine microfossil bonebed from the Upper Triassic MarayesEl Carrizal Basin, San Juan province. Palaios 30: 743-757.

Colombi, C.; Santi Malnis, P.; Correa, G.; Martínez, R.; Fernández, E.; Abelín, D.; Praderio, A.; Apaldetti, C.; Alcober, O. 2015b. La Formación Balde De Leyes (nov. nom.), una nueva unidad estratigráfica de la Cuenca Triásica de Marayes-El Carrizal. Revista de la Asociacion Geológica Argentina 72 (4): 445-455.

Colombo, F. 2010. Abanicos Aluviales: Secuencias y modelos de sedimentación. In Sedimentología del proceso físico a la cuenca sedimentaria (A. Arche; editor). Consejo Superior de Investigaciones Científicas: 131-183. Madrid.

Criado Roque, P.; Mombrú, C.A.; Ramos, V. 1981. Estructura e interpretación tectónica. In Geología y recursos naturales de la provincia de San Luis, Relatorio del Congreso Geológico Argentino, No. 8, Asociacion Geología Argentina: 155-192. Buenos Aires.

Damanti, J.F. 1993. Geomorphic and structural controls on facies patterns and sediment composition in a modern foreland basin. In Alluvial Sedimentation (Marzo, M.; Puigdefábregas, C.; editores). International 
Association of Sedimentologists, Special Publications 17: 221-233.

Davidson, S.K.; Hartley, A.J.; Weissmann, G.S.; Nichols, G.J.; Scuderi, L.A. 2013. Geomorphic elements on modern distributive fluvial systems. Geomorphology 180-181: 82-95.

DeCelles, P.G.; Cavazza, W. 1999. A comparison of fluvial megafans in the Cordilleran (Upper Cretaceous) and modern Himalayan foreland basin systems. Geological Society of American Bulletin 111: 1315-1334.

DeCelles, P.G.; Carrapa, B.; Horton, B.K.; Gehrels, G.E. 2011. Cenozoic foreland basin system in the central Andes of northwestern Argentina: Implications for Andean geodynamics and modes of deformation. Tectonics 30 (6): TC6013.

Friend, P. F. 1978. Distinctive features of some ancient river systems. Canadian Society of Petroleum Geologists Memoir 5: 531-542.

Gan, K.C.; McMahon, T.A.; Finlayson, B.L. 1992. Fractal dimensions and lengths of rivers in south-east Australia. The Cartographic Journal 29 (1): 31-34.

Gumbricht, T.; McCarthy, J.; McCarthy, T.S. 2004. Channels, wetlands and islands in the Okavango Delta, Botswana, and their relation to hydrological and sedimentological processes. Earth Surface Processes and Landforms 29 (1): 15-29

Gutiérrez Elorza, M. 2008. Geomorfología. Pearson Educación S.A.: 920 p. Madrid.

Gupta, S. 1997. Himalayan drainage patterns and the origin of fluvial megafans in the Ganges foreland basin. Geology 25 (1): 11-14.

Hartley, A.; Weissmann, G.; Nichols, G.; Scuderi, L. 2010. Fluvial form in modern continental sedimentary basins: Distributive fluvial systems: Reply. Geological Society of America, Geology Forum 38 (12): e231. doi.org/10.1130/G31588Y.1.

Hain, M.P.; Strecker, M.R.; Bookhagen, B.; Alonso, R.N.; Pingel, H.; Schmitt, A.K. 2011. Neogene to Quaternary broken foreland formation and sedimentation dynamics in the Andes of NW Argentina (25 $5^{\circ}$ S). Tectonics 30 (2): TC2006.

Hein, F.J.; Walker, R.G. 1977. Bar evolution and development of stratification in the gravelly, braided, Kicking Horse River, British Columbia. Canadian Journal of Earth Sciences 14: 562-570.

Horton, B.K.; DeCelles, P.G. 2001. Modern and ancient fluvial megafans in the foreland basin system of the central Andes, southern Bolivia: Implications for drainage network evolution in fold-thrust belts. Basin research 13 (1): 43-63.
Huete, A.R. 1988. A Soil-Adjusted Vegetation Index (SAVI). Remote Sensing of Environment 25: 295-309.

Hunter, R.E. 1977. Basic types of stratification in small eolian dune. Sedimentology 24: 361-387.

INTA, 2016. Sistema de Informacion y Gestión Agrometereológica. Disponible en: http://siga2.inta. gov.ar/ (Última visita 10/11/2016).

Iriondo, M.; Colombo, F.; Kröhling, D. 2000. El abanico aluvial del Pilcomayo, Chaco (Argentina-BoliviaParaguay): características y significado sedimentario. Geogaceta 28: 79-82.

Jackson, R.G. 1975. Hierarchical attributes and a unifying model of bed forms composed of cohesionless material and produced by shearing flow. Geological Society of America Bulletin 86 (11): 1523-1533.

Japas, M.S.; Cortés, J.M.; Pasini, M. 2008. Tectónica extensional triásica en el sector norte de la cuenca Cuyana: primeros datos cinemáticos. Revista de la Asociación Geológica Argentina 63 (2): 213-222.

Jofré, M.C. 2015. Procedencia de las sedimentitas del triásico superior de la formaciones Quebrada del Barro y Balde de Leyes, Cuenca de Marayes, el Carrizal, departamento Caucete, San Juan. Tesis de Licenciatura (Inédita), Facultad de Ciencias Exactas, Físicas y Naturales, Universidad Nacional de San Juan: $64 \mathrm{p}$.

Jordan, T.E.; Isacks, B.L.; Allmendinger, R.W.; Brewer, J.A.; Ramos, V.A.; Ando, C.J. 1983. Andean tectonics related to geometry of subducted Nazca plate. Geological Society of America Bulletin 94 (3): 341-361.

Jordensen, P.J.; Fielding, C.R. 1996. Facies architecture of alluvial floodbasin deposits: three-dimensional data from the Upper Triassic Callide Coal Measures of east-central Queensland, Australia. Sedimentology 43 (3): 479-495.

Kocurek, G. 1981. Significance of interdune deposits and bounding surfaces in aeolian dune sands. Sedimentology 28: 753-780.

Kocurek, G. 1988. First-order and super bounding surfaces in eolian sequences-bounding surfaces revisited. Sedimentary Geology 56 (1-4): 193-206.

Kocurek, G. 1991. Interpretation of ancient eolian sand dunes. Annual Review of Earth and Planetary Sciences 19 (1): 43-75.

Kocurek, G.; Havholm, K. G. 1993. Eolian sequence stratigraphy-a conceptual framework. MemoirsAmerican Association of Petroleum Geologists: 393 p.

Kraus, M. 1996. Avulsion deposits in lower Eocene alluvial rocks, Bighorn Basin, Wyoming. Journal of Sedimentary Research 66 (2): 354-363. 
Langford, R.P.; Chan, M.A. 1989. Fluvial-aeolian interactions: Part II, ancient systems. Sedimentology 36 (6): 1037-1051.

Leopold, L.B.; Wolman, M.G. 1957. River meanders patterns: braided, meandering and straight. Unites States Geological Surveys, Professional Papers 282B: 39-85.

Limarino, C.O.; Martínez, G. 1992. Caracterización textural de algunas mesoformas eólicas de ambientes semidesérticos en el Bolsón de Guandacol. In Reunión Argentina de Sedimentología, No. 4, Actas 2: 295 302. La Plata.

Lowe, D. 1982. Sediment gravity flows: 11. Depositional models with special reference to the deposits of highdensity turbidity currents. Journal of Sedimenteray Petrology 52: 279-297.

Makaske, B. 2001. Anastomosing rivers: a review of their classification, origin and sedimentary products. Earth-Science Reviews 53: 149-196.

McGlue, M.M.; Smith, P.H.; Zani, H.; Silva, A.; Carrapa, B.; Cohen, A.S.; Pepper, M.B. 2016. An Integrated Sedimentary Systems Analysis of the Río Bermejo (Argentina): Megafan Character in the Overfilled Southern Chaco Foreland Basin. Journal of Sedimentary Research 86: 1359-1377.

Miall, A.D. 1977. A review of the braided river depositional enviroment. Earth Science Reviews 13: 1-62.

Miall, A.D. 1985. Architectural-element analysis: A new method of facies analysis applied to fluvial deposits. Earth Science Reviews 22: 261-308.

Miall, A.D. 1988. Architectural elements and bounding surfaces in fluvial deposits: anatomy of the Kayenta Formation (Lower Jurassic), southwest Colorado. Sedimentary Geology 55 (3): 233-262.

Miall, A.D. 1996. The Geology of Fluvial Deposits Sedimentary Facies, Basin analysis, and Petroleum geology. Springer-Verlag Berlin Heidelberg: 582 p. Berlin.

Miliaresis, G.C.; Argialas, D.P. 2000. Extraction and delineation of alluvial fans from digital elevation models and Landsat Thematic Mapper images. Photogrammetric Engineering and Remote Sensing 66 (9): 1093-1101.

Mohrig, D.; Heller, P.L.; Paola, C.; Lyons, W.J. 2000. Interpreting avulsion process from ancient alluvial sequences: Guadalope-Matarranya system (northern Spain) and Wasatch Formation (western Colorado). Geological Society of America Bulletin 112 (12): 1787-1803.

Mosolf, J.G.; Horton, B.K.; Heizler, M.T.; Matos, R. 2011. Unroofing the core of the central Andean fold- thrust belt during focused late Miocene exhumation: evidence from the Tipuani-Mapiri wedge-top basin, Bolivia. Basin Research 23: 346-360.

Mougenot, B.; Pouget, M.; Epema, G. F. 1993. Remote sensing of salt affected soils. Remote Sensing Reviews 7 (3-4): 241-259.

Mountney, N.P. 2012. A stratigraphic model to account for complexity in aeolian dune and interdune successions. Sedimentology 59 (3): 964-989.

Nanson, G.C. 1980. Point bar and floodplain formation of the meandering Beatton River, northeastern British Columbia, Canada. Sedimentology 27: 3-29.

Nanson, G.C.; Croke, J.C. 1992. A genetic classification of floodplains. Geomorphology 4: 459-483.

Nanson, G.C.; Knighton, D.A. 1996. Anabranching rivers: their cause, character and classification. Earth Surface Processes and Landforms 21: 217-239.

Nichols, G.J.; Fisher, J.A. 2007. Processes, facies and architecture of fluvial distributary system deposits. Sedimentary Geology 195 (1): 75-90.

Olsen, H. 1989. Sandstone-body structures and ephemeral stream processes in the Dinosaur Canyon Member, Moenave Formation (Lower Jurassic), Utah, USA. Sedimentary Geology 61 (3-4): 207-221.

Orti Cabo, F. 2010. Evaporitas: introducción a la sedimentología evaporítica. In Sedimentología: Del proceso físico a la cuenca sedimentaria (Arche Miralle, A.; editor). Consejo Superior de Investigaciones Científicas: 675-769. Madrid

Pereyra, B. 1996. Clima de la provincia de San Juan. In Catálogo de Recursos Humanos e Información Relacionada con la Temática Ambiental en la Región Andina Argentina (Abraham, M.E.; Rodríguez Martínez, F.; editores). Publicación online C-Bra Systematics y GTZ. Buenos Aires. https://www.mendoza-conicet. gob.ar/ladyot/catalogo/cdandes/cap10.htm (Última visita 15/10/2016).

Raup, O.B. 1970. Brine Mixing: an additional mechanism for formation of basin evaporites. Bulletin of American Association of Petroleum Geologists 54: 2246-2259.

Reinfelds, I.; Nanson, G. 1993. Formation of braided river floodplains, Waimakariri River, New Zealand. Sedimentology 40: 1113-1127.

Regairaz, M.C. 2000. Suelos de San Juan. Argentina. In Recursos y problemas ambientales de la zona árida. Provincias de Mendoza, San Juan y La Rioja. Junta de Gobierno de Andalucía-Universidades y Centros de Investigación de La Región Andina Argentina: 59-62. Mendoza. 
Ross, G.M. 1983. Bigbear Erg: a Proterozoic intermontane eolian sand sea in the Hornby Bay Group, Northwest Territories, Canada. Developments in Sedimentology 38: 483-519.

Rosselló, E.A.; Mozetic, M.E.; Cobbold, P.R.; LópezGamundí, O.R. 1997. El Bolsón de Pagancillo (La Rioja, Argentina): una fosa tectónica constrictiva en un ambiente subandino y su relación con el lineamiento de Valle Fértil. In Simposio Bolivariano: Petroleum exploration in the Subandean basins, No 6, Actas 1: 32-45. Cartagena de Indias.

Rothis, L.M. 2016. Análisis de la actividad tectónica cuaternaria en el área sur de la falla Las Chacras y evaluación de la peligrosidad sísmica, Sierras Pampeanas Occidentales, provincia de San Juan. Tesis doctoral (Inédito), Universidad Nacional de San Juan: 211 p.

Rothis, L.M.; Santi Malnis, P.; Pantano Zúñiga, A.; Perucca, L.P. 2012. Evidencias de reactivación cuaternaria de la falla maestra triásica de Marayes, al norte del Cerro Pan de Azúcar, Sierras Pampeanas Occidentales, San Juan, Argentina. In Reunión de Tectónica San Juan, No. 15, Actas 1: p. 131. San Juan.

Rothis, L.M.; Perucca, L.P.; Santi Malnis, P; Pantano, A.; Esper, Y. 2015. Morfometría de la cuenca del Arroyo Papagayos y evaluación del peligro de avenidas. Departamento Caucete. Provincia de San Juan. In Congreso Argentino de Cuaternario y Geomorfología, No. 6, Libro de Resumenes: p. 313. Ushuaia.

Rust, B.R. 1972. Structure and process in a braided river. Sedimentology 18: 221-245.

Sabins, F. 1997. Remote Sensing. Principles and Interpretation. W.H. Freeman: 494 p. Nueva York.

Sánchez Rodríguez, E.; Torres Crespo, M.A.; Fernández Palacios Carmona, A.; Aguilar Alba, M.; Pino Serrato, I.; Granado Ruiz, L. 2000. Comparación del NDVI con el PVI y el SAVI como Indicadores para la Asignación de Modelos de Combustible para la Estimación del Riesgo de Incendios en Andalucía. Tecnologías Geográficas para el Desarrollo Sostenible. Universidad de AlcaláAsociación de Geográfos Españoles: 164-174.

Santi Malnis, P.; Colombi, C.; Limarino, C.; Rodríguez Posatini, N.; Rothis, L.M. 2016. The Papagayos Creek sedimentary enviroments, an example of a modern fluvial distributary system, eastern piedmont of $\mathrm{La}$ Huerta-Las Imanas Ranges, San Juan, Argentina. In Libro de Resúmenes del Congreso Latinoamericano de Sedimentología, No. 7, y Reunión Argentina de Sedimentología, No. 15 (Mehl A.E.; Bedatou, E.; editores). Asociación Argentina de Sedimentología: p. 151. Santa Rosa, La Pampa.
Scherer, C.M.; Goldberg, K. 2010. Cyclic cross-bedding in the eolian dunes of the Sergi Formation (Upper Jurassic), Recôncavo Basin: Inferences about the wind regime. Palaeogeography, Palaeoclimatology, Palaeoecology 296 (1): 103-110.

Sharp, R.P. 1963. Wind ripples. Journal of Geology 71: 617-636.

Shultz, A.W. 1984. Subaerial Debris-Flow Deposition in the Upper Paleozoic Cutler Formation, Western Colorado. Journal of Sedimentary Petrology 54 (3): 0759-0772.

Slingerland, R.; Smith, N. 2004. River avulsions and their deposits. Annual Review of Earth and Planetary Sciences 32: 257-285.

Smith, D.G.; Hubbard, S.M.; Leckie, D.L.; Fustic, M. 2009. Counter point bar deposits: lithofacies and reservoir significance in the meandering modern Peace River and ancient McMurray Formation, Alberta, Canada. Sedimentology 56: 1655-1669.

Smith, N.D. 1970. The braided stream depositional environment: comparison of the Platte River with some Silurian clastic rocks, north-central Appalachians. Geological Society of America Bulletin 81 (10): 2993-3014.

Spalletti, L.A.; Colombo Piñol, F. 2005. From Alluvial Fan to Playa: An Upper Jurassic Ephemeral Fluvial System, Neuqukn Basin, Argentina. Gondwana Research 8 (3): 363-383.

Suriano, J.; Limarino, C. 2009. Sedimentación pedemontana en las nacientes del Río Jáchal y Pampa de Gualilán, Precordillera de San Juan. Revista de la Asociación Geológica Argentina 65 (3): 516-532.

Suriano, J.; Limarino, C.O.; Tedesco, A.M.; Alonso, M.S. 2015. Sedimentation model of piggyback basins: Cenozoic examples of San Juan Precordillera, Argentina. Geological Society London, Special Publications 399 (1): 221-244.

Suvires, G.H. 1986. Campos de dunas en el CentroOeste Argentino. In Simposio Latino-Americano de Sensoriamento Remoto, No 4. Actas 1: 10-15. Gramado.

Suvires, G. 1996. Geomorfología de la Provincia de San Juan. In Catálogo de recursos humanos e información relacionada con la temática ambiental en la Región Andina Argentina (Abraham, M.E.; Rodríguez Martínez, F.; editors) Publicación online C-Bra SystematicsGTZ. Buenos Aires. https://www.mendoza-conicet. gob.ar/ladyot/catalogo/cdandes/cap11.htm (Última visita 20/06/2017).

Suvires, G.M. 2014. The paradigm of paraglacial megafans of the San Juan river basin, Central Andes, 
Argentina. Journal of South American Earth Sciences 55: 166-172.

Tedesco, A.M.; Limarino, C.O.; Tripaldi, A.; Suriano, J. 2013. Dinámica de la depositación de los depósitos de tope de cuña (wedge top deposits) de la Formación El Corral, provincia de La Rioja, Argentina. Revista Mexicana de Ciencias Geológicas 30: 552-568.

Tripaldi, A. 2002. Sedimentología y evolución del campo de dunas de Médanos Grandes (provincia de San Juan, Argentina). Revista de la Asociación Argentina de Sedimentología 9 (1): 65-82.

Tripaldi, A.; Forman, S.L. 2007. Geomorphology and chronology of Late Quaternary dune fields of western Argentina. Palaeogeography, Palaeoclimatology, Palaeoecology 251 (2): 300-320.

Tripaldi, A.; Limarino, C.O. 2008. Ambientes de interacción eólica-fluvial en valles intermontanos: ejemplos actuales y antiguos. Latin American Journal of Sedimentology and Basin Analysis 15 (1): 43-66.
Tripaldi, A.; Net, I.A.; Limarino, C.O.; Marenssi, S.A.; Re, G.; Caselli, A.T. 2001. Paleoambientes sedimentarios y procedencia de la Formación Vinchina, Mioceno, noroeste de la provincia de La Rioja. Revista de la Asociación Geológica Argentina 56: 443-465.

Tunbridge, I.P. 1981. Sandy high-energy flood sedimentationsome criteria for recognition, with an example from the Devonian of SW England. Sedimentary Geology 28 (2): 79-95.

Vujovich, G.I.; Chernicoff, C.J.; Tchilinguirian, P.; Godeas, M.; Marín, G.; Pezzutti, N.; Sepúlveda, E.; Cardó, R.; Díaz, I. 2007. Hoja Geológica 3166 - III Chepes. Provincias de La Rioja, San Juan y San Luis. Instituto de Geología y Recursos Minerales, Servicio Geológico Minero Argentino 251: 65 p. Buenos Aires. Weissmann, G.S.; Hartley, A.J.; Nichols, G.J.; Scuderi, L.A.; Olson, M.; Buehler, H.; Banteah, R. 2010. Fluvial form in modern continental sedimentary basins: Distributive fluvial systems. Geology 38 (1): 39-42. 
Anexo

\title{
Zonación del arroyo Papagayos
}

\author{
Zona proximal: formas y facies asociadas
}

\section{Área canalizada}

\section{Formas de lecho gravosas y arenosas (SGB-LS)}

Son acumulaciones gravosas y arenosas y de bloques aislados, caracterizadas por las litofacies $\mathrm{Gcm}$ con matriz sabulosa, Sh, Sm, Sr y Flc y Ev, que se ubican en las zonas más profundas del lecho de los cauces (Fig. 6a, b, c). Presentan una base plana y cepillada la que representaría una superficie limitante de orden cinco, con morfología tabular a plana (Miall, 1996). En general, el aspecto que evidencia es un cuerpo plano, que por sectores tiene surcos longitudinales en dirección aguas abajo (Fig. 6a). Las litofacies Gcm se encuentra formando lenguas, constituidas por clastos de $5 \mathrm{~cm}$, con clastos sabulosos en los intersticios. Aisladamente aparecen bloques de hasta $0,80 \mathrm{~m}$. Las litofacies arenosas macizas medianas y gruesas, forman mantos en las partes centrales del lecho (Fig. 6a). En cambio, las arenas laminadas aparecen en los bordes del lecho fluvial, y en los cauces secundarios (Sh; Fig. 6b). Las mismas están cubiertas por una película muy fina de arcillas, de escasos milímetros de espesor, en las que se preservan impresiones de gotas de lluvia y por lámina pulverulentas de sales (Flc, Ev; Fig. 6c). Los valores del índice SAVI en este elemento son mínimos a nulos.

Interpretación: las formas de lecho gravo-arenosas registran diferentes estadios del régimen de flujo de corriente. En el pico de la creciente, se depositan bloques aislados y lenguas de gravas, en condiciones de alto régimen de flujo como una carga de lecho transportada por rolido, correspondiendo con el estadio inicial de la generación de barras longitudinales (Hein y Walker, 1977). Los depósitos de arenas macizos (sábulos y arenas gruesas) se ubican en sectores más centrales o de mayor relieve dentro del lecho fluvial y son el producto de flujos de gravedad no cohesivos asociados a una disminución de la capacidad de la corriente por infiltración (Miall, 1996). Las litofacies Sh se depositan con régimen de flujo plano o crítico, generando laminación paralela en los cauces más profundos (Ashley, 1990; Miall, 1996). El decrecimiento del régimen de flujo está representado por cortinas de fango en pequeños charcos o en el thalweg (Rust, 1972). La precipitación de láminas o parches de evaporitas en forma pulverulenta o muy fina respondería a condiciones climáticas áridas, con extrema evaporación al cese de la corriente.

\section{Hoyos (HO)}

Se desarrollan en el lecho del cauce en sectores donde hay erosión (curva del río), o en la unión aguas abajo de dos cauces separados por una barra longitudinal. Estos hoyos o piletones, de hasta $0,50 \mathrm{~m}$ de profundidad y $1 \mathrm{~m}$ de ancho, están rellenos con litofacies arenosas y limosas de tipo Sh y Sm, de arenas gruesas a medias, con cortinas de fango (Flc) de escasos milímetros en las que se preservan gotas de lluvia.

Interpretación: la generación de estos piletones se produce en condiciones de alto régimen de flujo, por la erosión generada debido a la rotación de vórtices espiralados durante la crecida y luego su relleno en condiciones de menor energía durante el cese de la descarga (Olsen, 1989). Pueden formarse durante un solo evento de arroyada en manto (Miall, 1996). Los hoyos o piletones observados son similares a los descritos por Olsen (1989) y de menor escala a los que describe Miall (1996).

\section{Barras longitudinales (GB)}

Son depósitos de gravas dispuestas en cuerpos achatados de aproximadamente $100 \mathrm{~m}$ de longitud por $15 \mathrm{~m}$ de anchura y $0,30 \mathrm{~m}$ de alto, que se disponen en la parte central de cauce principal siendo rodeadas en ambos márgenes por cauces (Fig. 6d). Están limitadas en su base por una superficie limitante de quinto orden. Internamente, se observan superficies limitantes de segundo orden y en el techo de las barras presentan ondulaciones interpretadas como la progradación de la macroforma aguas abajo, por lo que correspondería con una superficie de tercer orden. Está formada por un arreglo granodecreciente con las litofacies Gcm, 
a veces $\mathrm{Gmm}$ con matriz sabulosa, con acumulaciones arenosas lenticulares (Sh) en las caras de sotavento y más gruesas en las caras de barlovento (Fig. 6d, e y f). Los clastos varían de 5 a $20 \mathrm{~cm}$ de longitud a lo largo de su eje mayor, estando los más gruesos dispuestos en el núcleo. La cara frontal está pobremente preservada, ya que es erosionada por el cauce que la rodea, pero cuando se preserva está formada por arena gruesa a sábulo maciza o con laminación difusa. Son muy similares a las descritas por Hein y Walker, (1977), de escaso relieve o expresión topográfica dentro del cauce.

Interpretación: las barras longitudinales gravosas están generadas por el apilamiento de carpetas tractivas (difuse gravel sheet Hein y Walker, 1977). Es posible que la preservación de las caras de avalancha en este elemento a diferencia de las barras descritas por Hein y Walker (1977) se relacione con el carácter efímero del arroyo Papagayos y la rápida caída de la energía que genera estas formas de lecho, inhibiendo su erosión una vez depositadas.

\section{Barras longitudinales vegetadas $(\mathrm{DA})$}

Son cuerpos que se disponen en el centro del cauce y presentan una topografía marcada, y dimensiones de 80 a $200 \mathrm{~m}$ de largo, por 15 a $50 \mathrm{~m}$ de ancho y alturas entre el $1 \mathrm{~m}$ y 1,5 m. En las más altas se observan algunos árboles ubicados en el extremo anterior mirando aguas abajo, y en las más bajas vegetación arbustiva (Fig. $6 \mathrm{~g} \mathrm{y} \mathrm{h).} \mathrm{En} \mathrm{su} \mathrm{arreglo} \mathrm{interno} \mathrm{se} \mathrm{observan} \mathrm{superficies} \mathrm{de} \mathrm{orden} \mathrm{tres,} \mathrm{pertenecientes} \mathrm{al} \mathrm{tipo} \mathrm{DA} \mathrm{muy}$ marcadas, indicando el crecimiento aguas abajo de la macroforma. Las litofacies que las componen son Gcm con bloques, en cuerpos tabulares a lentiformes y por encima $\mathrm{Sh} \backslash \mathrm{Sl}$ de arena media a fina, con retrabajamiento eólico en la parte superior (generando gradación inversa Sg; Fig. 6i). Este elemento presenta abundantes y largas raíces leñosas en las litofacies gravosas.

Interpretación: su construcción se inicia a partir de un núcleo gravoso de manto de gravas de estructura difusa, y luego crece verticalmente con arreglo granodecreciente, con la generación de cosets de Sh y Sl a medida que decrece la energía del flujo (Hein y Walker, 1977; Ashmore, 1991; Miall, 1996). Entre las estaciones lluviosas el viento modifica los sedimentos arenosos depositados, generando pequeñas óndulas de arena en arenas finas (sand ripples; Sharp, 1963), similar a los parches de arena mencionados por Tripaldi y Limarino (2008) que se generan por clastos que se transportan por saltación con acumulación de clastos más gruesos y pesados en las crestas (Bagnold, 1954; Anderson, 1987; Kocurek, 1991).

\section{Barras alternas gravosas (BAG)}

Son acumulaciones de gravas gruesas y bloques imbricados (Gci-Bci) en lentes de unos $15 \mathrm{~m}$ de longitud por 3 a $4 \mathrm{~m}$ de ancho, y 0,50 $\mathrm{m}$ de altura, ubicados en los sectores laterales del cauce (Fig. 6j y k). Están tapizados por mantos de arenas medias a finas macizas, que se ubican entre los clastos, y hacia el borde superior del depósito.

Interpretación: la formación de estas barras gravosas se produce en condiciones de alto régimen de flujo, en el pico de la creciente, los bloques y gravas gruesas son trasladados por rolido (Rust, 1972; Hein y Walker, 1977). Su acumulación se produce en los bordes del lecho fluvial, cuando la fricción entorpece el avance de los mismos hasta su detención. En un estadio posterior cuando decrece el régimen de flujo se deposita arena media a fina maciza o con laminación difusa, rellenando los intersticios entre clastos, como una matriz secundaria, y cubriendo los depósitos de un estadio de mayor energía (Rust, 1972).

\section{Área de llanura de inundación}

\section{Desbordamientos proximales (PCS)}

Son depósitos de gravas gruesas y arenas que forman acumulaciones acrecionadas en cuerpos de $750 \mathrm{~m}$ de longitud por $215 \mathrm{~m}$ de anchura, con una topografía de aspecto plano a convexa de $0,20 \mathrm{~m}$ hasta $1,80 \mathrm{~m}$ de alto. Se disponen en los sectores laterales del cauce principal, y son surcadas y/o rodeadas por cauces secundarios de menor tamaño (Fig. 7). Las superficies limitantes que se observan internamente son las de segundo orden, mientras que el techo de la macroforma es convexo y representaría la superficie limitante de cuarto orden (4c). Están compuestas por ciclos heterolíticos: Gcil $\mathrm{S}(\mathrm{G}) \mathrm{m}-\mathrm{S}(\mathrm{G}) \mathrm{h}$ y, por encima, tapizando la macroforma, la litofacies Fm. Presenta gran concentración de vegetación en comparación a las otras 
macroforma descritas para este sector. La vegetación es de tipo arbustiva principalmente con valores de SAVI medios a bajos entre 0,17 y 0,32 .

Interpretación: estos cuerpos han sido interpretados como lóbulos de desbordamiento proximales. Los mismos se inician con clastos depositados por rolido en alto régimen de flujo (lentes gravas con imbricación), y luego cuando el régimen de flujo disminuye se depositan arenas gravosas y sábulos con una difusa estratificación horizontal. La ausencia de superficies de erosión internas y raíces sugiere una rápida depositación y progradación (Bristow et al., 1999). La morfología de estos lóbulos es similar a la reportada por Bristow et al. (1999) en ríos entrelazados de carga arenosa, desarrollándose el desbordamiento en forma paralela al canal principal (Jordensen y Fielding, 1996; Bristow et al., 1999).

\section{Zona media: formas y facies asociadas}

\section{Área canalizada}

\section{Formas de lecho arenosas (SB)}

Las formas de lecho arenosas están representadas por ondas de arena, y mesoformas gravo-arenosas de morfología lobulada y de poco relieve entre 0,50 a $1 \mathrm{~m}$ de espesor, con litofacies $\mathrm{Sp}, \mathrm{St}$ (achatadas), Gcm en forma secundaria y Sr, Flc en forma de cortinas de fango (Fig. 8a, b).

Interpretación: en las porciones más profundas de canales activos se produce la migración de dunas 3D, generando lóbulos de arenas (channel floor dune fields, Miall, 1996). Las cortinas de fango indican la depositación en condiciones de decaimiento del régimen de flujo cuando la corriente ha cesado (e.g., Smith, 1970; Miall, 1996).

\section{Hoyos (HO)}

Nuevamente se observan piletones asociados a sectores donde hay vegetación prominente o barras longitudinales que obstaculizan el flujo de la corriente, similares a los descritos en el apartado anterior.

\section{Barras longitudinales arenosas (BLA)}

Son similares a las observadas en la zona 1. Presentan dimensiones de $200 \mathrm{~m}$ de longitud por $40 \mathrm{~m}$ de anchura y alturas de hasta $0,50 \mathrm{~m}$, tienen morfología lingüoide y están rodeadas por cauces activos (Fig. 5 y 8a). En general, se observa una clara gradación vertical de grava a arena y superficies de migración aguas abajo de la macroforma (DA) y el foreset preservado. El arreglo de facies comprende gravas masivas en la base y rellenando las estructuras de corte y relleno $(\mathrm{Gcm})$ y gravas finas junto con litofacies arenosas con estratificación horizontal en la parte superior (Gh, S(G)m y Sh-Sl).

Interpretación: las barras longitudinales arenosas están generadas por el apilamiento de carpetas tractivas (Hein y Walker, 1977). Son de muy poco relieve, con foresets preservados, similares a las descritas por Hein y Walker (1977).

\section{Barras longitudinales vegetadas $(\mathrm{DA})$}

Son similares a las descritas en el apartado anterior. En las porciones en que el cauce principal es estrecho (12 m) y está ramificado en varios cauces separados por grandes áreas de depositación, las barras longitudinales presentan dimensiones de hasta $150 \mathrm{~m}$ de longitud por $50 \mathrm{~m}$ de anchura y alcanzan hasta $1 \mathrm{~m}$ de espesor (Fig. 5). En su estructura interna se destacan las superficies de acreción aguas abajo más marcadas que en el elemento anterior debido a la mayor altura que alcanzan estas barras. Las mismas están formadas por las litofacies Gci, Gh, S(G)m y SIISt y Sh en forma minoritaria (Fig. 8c, d, e, f). Estas macroformas presentan vegetación arbustiva e incluso arbórea, con valores de SAVI de 0,32 a 0,47 , alcanzando aisladamente valores de hasta 0,62 .

Interpretación: la formación de las barras longitudinales vegetadas es similar a los procesos descritos por Hein y Walker (1977). Inicialmente se depositan mantos de gravas difusos, por la acumulación de la carpeta tractiva. Luego, al agradar verticalmente y aguas abajo, favorecen la depositación de litofacies de menor régimen de flujo como Sh, Sl y St (Hein y Walker, 1977; Miall, 1996). 


\section{Counter point bar (CPB)}

Se disponen en los bordes externos convexos del cauce principal y se caracterizan por formar cuerpos lobulados y de morfología sigmoidea, que se acrecionan lateralmente con dimensiones de $230 \mathrm{~m}$ de longitud y $50 \mathrm{~m}$ de anchura (Fig. 5). Están formados por litofacies $\mathrm{Gcm}, \mathrm{S}(\mathrm{G}) \mathrm{m}$ y litofacies arenosas medias a finas con diferentes estructuras, Sl, Sm (Fig. 8e, g y h). Finalmente, están cubiertos por litofacies arcillosas, Fl. En estas geoformas se desarrollan cuevas de vertebrados y abundante vegetación, con valores de índice SAVI se encuentran entre 0,32 a 0,47 .

Interpretación: estos cuerpos son interpretados por su morfología, arreglo facial y posición respecto al canal activo, como barras desarrolladas en el margen opuesto a una barra en espolón (Nanson y Croke, 1992). El desarrollo de estas barras, con meandros de gran amplitud, ha sido vinculada a la presencia de bordes resistentes que impiden la migración lateral del meandro (Smith et al., 2009). La presencia de estos cuerpos podría estar vinculada a la resistencia que ofrecen las paredes de los albardones que confinan la faja canalizada en este sector del sistema donde alcanzan los 1,5 $\mathrm{m}$ de altura.

\section{Área intercanal (AI)}

Esta región está formada por depósitos que quedan limitados por canales activos, dentro de la faja canalizada. El relleno de los mismos corresponde a barras longitudinales que crecen en altura y luego son cubiertas por depósitos de desbordamiento.

Esta área posee dimensiones que exceden los $3.000 \mathrm{~m}$ de longitud por 150 a $450 \mathrm{~m}$ de anchura y alturas de 1,5 a 1,8 m (Fig. 5). Está formada por depósitos que tienen morfología lingüoide y alargada, y presentan pequeños cauces que las drenan (Fig. 5). En este sector se pueden discriminar dos etapas de relleno, separadas por una superficie limitante de cuarto orden. Una inicial que corresponde a una barra longitudinal arenosa (ciclos grano-estrato decrecientes $\mathrm{Gh}-\mathrm{Sl}$ ) similar a las descritas anteriormente y una segunda etapa que corona la anterior formada por depósitos finos de desbordamiento (Sm-Fm-Sr). Por otra parte, es importante destacar que en el área intercanal se observa gran cantidad de árboles y arbustos, con valores de SAVI desde 0,32 a 0,77 . Este elemento presenta abundantes raíces leñosas.

Interpretación: la etapa inicial del relleno comienza como un manto de gravas de estratificación difusa (Hein y Walker, 1977). Luego, se produce una rápida acreción vertical de capas de gravas finas y arenas gruesas estratificadas, que debido al poco tiempo transcurrido en la formación del depósito no están afectadas por bioturbación (Bristow et al, 1999). Por encima, una superficie de cuarto orden correspondiente al techo de la barra separa la segunda etapa de relleno formada por depósitos heterolíticos generados por desbordamientos.

\section{Área de llanura de inundación}

Este sector está compuesto por albardones, lóbulos de desbordamiento, canales alimentadores de lóbulo de desbordamiento y canales secundarios. Predominan los materiales areno-arcillosos con gravas aisladas.

\section{Sistema de canales entrelazados embrionarios (CEE)}

Se desarrolla una red de canales distributarios entrelazados conectados al canal principal con un ángulo de divergencia respecto al sistema principal de unos $20^{\circ}$ (Fig. 5). Estos canales son poco profundos y están rellenos de materiales gravo-arenosos e irrigan la llanura de inundación. En general, se desarrollan en los sectores donde los albardones tienen poca altura. Es común observar que el avance de esta red de canales, o su progradación dentro de la llanura de inundación terminará conectándose con la red de canales generados por erosión retrocedente (CHm ver a continuación).

Interpretación: sistemas de canales similares han sido descritos en la bibliografía asociados a los procesos de avulsión y se los asocia con procesos de agradación rápida (Mohrig et al., 2000). La inundación o el desborde del sistema canalizado principal en las áreas de llanura de inundación genera inicialmente una red de canales poco organizada e ineficiente, aunque si luego se conecta con los sistemas de canales generados por erosión retrocedente (ver a continuación) resultarán en una avulsión exitosa del canal principal (Mohrig et al., 2000; Slingerland y Smith, 2004). 


\section{Albardones (LV)}

Este elemento está formado por depósitos tabulares a cuneiformes que disminuyen su espesor desde el cauce principal hacia la llanura, con una dimensión de $500 \mathrm{~m}$ de longitud por unos $45 \mathrm{~m}$ de anchura, y hasta 1,5 m de altura (Figs. 5 y 9a, e). Generan una notable elevación de la topografía en los bordes del canal. Internamente, presentan superficies limitantes de primer y segundo orden, y externamente la superficie limitante 4c. Están compuestos por niveles intercalados de arenas y arcillas con algunos clastos aislados de sábulos, $\mathrm{S}(\mathrm{G}) \mathrm{m}, \mathrm{Sm}-\mathrm{F}(\mathrm{S}) \mathrm{m}-\mathrm{Fm}$ (Fig 9c); F(S)m, F(G)m, culminando en el techo con la litofacies $\mathrm{Sr}$ (Figs. 9d). Presentan abundantes raíces y la vegetación alcanza valores de SAVI de 0,47 a 0,62 (Fig. 9a). En esta macroforma se observan huesos de vertebrados esparcidos en su superficie y/o parcialmente cubiertos por los depósitos arcillo-arenosos, al igual que abundantes huellas (Fig. 9b).

Interpretación: el aspecto rítmico y la morfología de estos depósitos han sido interpretados como eventos de inundaciones sucesivas en los que el flujo desborda el canal y al perder competencia genera el albardón (Miall, 1996). Los flujos densos cohesivos $(\mathrm{F}(\mathrm{S}) \mathrm{m}$ y $(\mathrm{F}(\mathrm{G}) \mathrm{m})$ forman parte de los ciclos heterolíticos y se producen cuando las aguas del canal activo son desbordadas sobre sedimentos altamente permeables que generan una rápida infiltración y concentración de sedimentos en los flujos, los que por la fuerza que adquiere la matriz, pueden seguir llevando partículas gruesas en suspensión (Shultz, 1984; Colombi et al., 2015a).

\section{Canal de lóbulo de desbordamiento $C R$}

Son depresiones alargadas, $20 \mathrm{~m}$ de anchura por $200 \mathrm{~m}$ de longitud, que conectan el canal principal con los lóbulos de desbordamiento (Figs. 5 y 10a). Se caracterizan por una disminución notable de la concentración de la vegetación con respecto a su entorno, abundancia de limos y arcillas con clastos dispersos, $\mathrm{F}(\mathrm{S}) \mathrm{l}-\mathrm{F}(\mathrm{S}) \mathrm{m}$, $\mathrm{F}(\mathrm{G}) \mathrm{m}$, con grietas de desecación y abundantes micas (Fig. 10b). En ellos se observan lenguas de gravillas matriz soportadas y arenas macizas con clastos sabulosos y gravas aisladas $\mathrm{S}(\mathrm{G}) \mathrm{m}$ (Fig. 10c).

Interpretación: los canales de desbordamiento se generan por el rompimiento de la pared del albardón durante la crecida de un río. Uno de los procesos formadores es denominado avulsión por incisión (Mohrig et al., 2000; Slingerland y Smith, 2004). Este proceso se produce por un estadio inicial de erosión retrocedente en el albardón, generando un canal inciso el que luego es ocupado por el flujo durante la creciente. Este flujo es direccionado hacia la llanura de inundación por la diferencia de potencial entre el albardón y las áreas deprimidas de la llanura de inundación (Mohrig et al., 2000).

\section{Lóbulos de desbordamiento $\left(C S_{M F}\right)$}

Son depósitos ligeramente convexos, con forma lobulada de aproximadamente $700 \mathrm{~m}$ de longitud por $600 \mathrm{~m}$ de anchura, aunque frecuentemente se amalgaman, obliterando la dimensión real (Figs. 5 y 10a). Estos depósitos alcanzan el metro de espesor y están conectados al cauce a través del canal alimentador o canal de lóbulo de desbordamiento (CR), el cual no siempre preserva su morfología, al ser interrumpido temporalmente por los depósitos de albardón. Pueden diferenciarse claramente dos sectores, un sector de lóbulo proximal y un sector de lóbulo distal. En general están formados por intercalación de cuerpos tabulares de litofacies arenosas y arcillosas con sábulos aislados, $\mathrm{Sm}-\mathrm{Sr}-\mathrm{F}(\mathrm{G}) \mathrm{m}-\mathrm{F}(\mathrm{S}) \mathrm{m}$, y lentes aislados de gravas finas $\mathrm{Gcm}$ (Figs. 10b y c).

En el sector proximal se desarrollan depósitos con morfología de lenguas de arenas $\mathrm{S}(\mathrm{G}) \mathrm{m}$, y aglomerado fino $(\mathrm{Gmm})$, y se observan clastos aislados dispersos en el material arcilloso $(\mathrm{F}(\mathrm{G}) \mathrm{m})$. Es común observar en la superficie de este elemento el desarrollo de grandes cuevas con cámaras de vertebrados de pequeño y mediano porte y abundantes heces (Fig. 10d). La vegetación presenta una distribución uniforme y concentrada, y hay abundante desarrollo de vegetación herbácea, siendo el índice SAVI de valores entre 0,17 y 0,32 .

En su parte distal los lóbulos de desbordamiento generan un relieve de suaves lomadas formada por litofacies arcillosas maciza a pobremente laminada, $F(G) m$.

Interpretación: el arreglo facial y la morfología de los cuerpos observados sugieren que este elemento se produjo por flujos en arroyadas en manto, de tipo laminar y muy cohesivos que avanzan sobre la llanura de inundación. Se producen debido a la ruptura de la pared de los albardones, luego de perder el confinamiento del canal de lóbulo de desbordamiento (Kraus, 1996, tabular bodies de Makaske, 2001). 


\section{Canales secundarios por erosión retrocedente $(\mathrm{CHm})$}

En la llanura de inundación se observa una red de canales estrechos $(2 \mathrm{~m})$ y poco profundos $(0,50 \mathrm{~m})$ rellenos de sábulos y arenas en litofacies $\mathrm{S}(\mathrm{G}) \mathrm{m}$ y Gcm (Fig. 10d y e). En los bordes se concentra vegetación, $y$ en su interior se observan algunos arbustos. En general presentan valores de SAVI de 0,17 a 0,32. Son principalmente erosivos, dominados por estructuras de corte y relleno. Algunos de ellos se profundizan por erosión retrocedente en las partes inactivas de la llanura.

Interpretación: son formados por el escurrimiento de agua superficial durante tormentas y/o grandes crecidas del río, donde las arroyadas en manto que cubren gran parte de la llanura, comienzan a escurrir por las zonas más deprimidas erosionando el material arcilloso rápidamente removible. Estos canales tienden a distribuir el agua dentro de la llanura y algunos llegan a encauzar el agua hasta un canal activo de mayor orden dentro de la red de drenaje (Makaske, 2001; Nichols y Fisher, 2007). La erosión retrocedente de estos canales puede conectarse con los sistemas de canales entrelazados embrionarios resultando en la avulsión del sistema fluvial (Mohrig et al., 2000).

\section{Zona distal: formas y facies asociadas}

\section{Área canalizada}

\section{Formas de lecho arenosas}

Son similares a las descritas en la zona 2. En este caso predominan las mesoformas de litofacies St (Fig. 11a), Sr, aunque también hay lentes Gcm.

Interpretación: en las porciones más profundas de canales activos se produce la migración de dunas 3D, generando lóbulos de arenas (channel floor dune fields, Miall, 1996). Las litofacies Sr y Fl indican la depositación en condiciones de decaimiento del régimen de flujo (e.g., Smith, 1970; Miall, 1996).

\section{Barras de acreción lateral arenosas (LA)}

Son acumulaciones arenosas a areno-fangosas, raramente gravosas, dispuestas en cuerpos de morfología en espolón (Fig. 5). Estas barras presentan un largo promedio de $200 \mathrm{~m}$, alcanzando un máximo de $440 \mathrm{~m}$, y un ancho de 100 a $140 \mathrm{~m}$. En planta puede observase la morfología de surco y cresta y en perfil la superficie de acreción lateral característica de la barra de meandro. Internamente, se observa un depósito residual basal gravoso y por encima, entre las superficies de tercer orden, presentan un arreglo grano-decreciente desde arena a fangos (Sm, Sp, St); y por encima Sr-Fl (Fig. 11b, c, d, e). Hacia el techo, presentan bioturbación intensa, lentes rellenos de hojas y otros rellenos de sales (Fig. 11e y f). Estas macroformas presentan valores muy bajos SAVI, menor a 0,028 . Ocasionalmente, cuando se produce el pasaje de un tramo recto del cauce principal a un tramo curvo, se genera una acumulación anómala de restos de árboles y arbustos apilados (Fig. 11f).

Interpretación: la caracterización de estos depósitos coincide con las barras en espolón de Nanson (1980), las cuales se generan por la depositación de sedimentos en las curvas convexas de ríos sinuosos por el flujo espiralado que caracteriza a los mismos. Estas barras inician con el desarrollo de una plataforma depositada primariamente por carga traccional y luego una sucesión intermitente de carga en suspensión. En un estadio inmediatamente posterior a la crecida, decantan hojas y arcillas en pequeños charcos (true suspension sediment, Nanson, 1980) y finalmente precipitan sales evaporíticas favorecidas por la aridez del clima.

\section{Mantos de arenas laminadas (LS)}

Son depósitos dominantemente arenosos y con algunas gravas aisladas o en forma de pequeños lentes, de morfología tabular de poca altura 0,30-0,50 cm que se ubican en el lecho de los canales activos (Fig. 11f y g). El techo de los depósitos es plano, e internamente se observan algunas superficies limitantes de segundo orden y superficies de cuarto orden mostrando la superposición de eventos torrenciales. El arreglo facial que presentan está dado por las litofacies Gh-S(G)l-S(G)h (Fig. 11g); Sh-Sr-Fl .

Interpretación: este elemento arquitectural se produce por flujos torrenciales no canalizados que se depositan en condiciones de alto régimen de flujo-flujo crítico y genera un lecho fluvial plano, depositando 
cuerpos de sedimentos con morfología achatada y tabular (Miall, 1977; Tunbridge, 1981; Miall, 1996). Las litofacies Sr y Fl indican rápida depositación en condiciones de flujo menguante durante la finalización del evento de crecida, con escaso o nulo retrabajamiento en condiciones de bajo régimen de flujo (Tunbridge, 1981).

\section{Hoyos}

Nuevamente se observan piletones asociados a sectores donde hay vegetación prominente que obstaculizan el flujo de corriente.

\section{Área de llanura de inundación}

\section{Albardones (LV)}

Son similares a los descritos en la zona 2 (Figs. 5 y 12a). El techo de estos depósitos está coronado por abundantes arbustos cuyas raíces penetran hasta $0,50 \mathrm{~m}$ bajo la superficie y aparecen abundantes cuevas de vertebrados. El índice SAVI es de 0,17 a 0,32 e incluso alcanza valores de 0,47.

\section{Lóbulos de desbordamiento $C S_{(M F)}$}

Este elemento es similar al descrito en la zona 2, con mayores dimensiones (1.000 $\mathrm{m}$ de ancho por $1.250 \mathrm{~m}$ de largo) y se observan en forma secundaria dentro de la llanura de inundación.

\section{Lóbulos de desbordamiento terminal (MF)}

Son acumulaciones fangosas principalmente, con gravilla aislada o en forma de lentes centimétricos, que se disponen en los sectores terminales de los canales principales y secundarios formando cuerpos lobulares elongados en la dirección de los ríos, progradadando hacia el sector distal de la llanura (Figs. 5, 12b, c y d). Los cuerpos presentan morfología marcadamente convexa en el sentido longitudinal y transversal (Fig. 12d), y alcanzan hasta $2 \mathrm{~m}$ de espesor (Fig. 12a, c). Están formados por la sucesión de ciclos granocrecientes que comienzan con capas de $0,50 \mathrm{~m}$ de espesor de litofacies arcillosas con clastos aislados de sábulos y gravas de hasta $7 \mathrm{~cm}, \mathrm{~F}(\mathrm{G}) \mathrm{m}$; seguidos por capas de $0,20 \mathrm{~m}$ de litofacies areno gravosas con laminación, $\mathrm{S}(\mathrm{G}) \mathrm{l}$; por encima aparecen cuerpos lentiformes de $0,10 \mathrm{~m}$ de espesor de litofacies gravosas masivas, Gcm y, en el techo del elemento aparecen láminas de sales, Ev. La vegetación presenta valores de SAVI variables, alcanzando los lóbulos cercanos al canal activo valores de hasta 0,62 , mientras que aquellos que se ubican lejanos al canal activo poseen valores de SAVI muy bajos (menor a 0,028 ).

Interpretación: las capas tabulares gravosas se depositan por procesos de flujos en manto en ríos que han perdido el confinamiento al llegar a una zona de muy baja pendiente inhibiendo la canalización (Miall, 1977; Tunbridge, 1981). Las litofacies F(G)m se hace más común que en otros sectores del SFD del arroyo Papagayos, probablemente vinculado a la abundante proporción de arcillas traídas en suspensión por las corrientes al alcanzar el sector distal. Estos depósitos podrían ser el resultado de flujos hiperconcentrados cohesivos plásticos a pseudoplásticos, en los que grandes proporciones de material arcilloso actúan como mecanismo de sostén de los clastos más gruesos a través del proceso de resistencia de la matriz (Shultz, 1984; Tedesco et al., 2013; Colombi et al., 2015a). La depositación se produce por "congelamiento cohesivo" causado por el adelgazamiento o desaparición de la zona de cizalla basal debido a la disminución de la pendiente, del espesor o del contenido de agua, o la combinación de estos tres factores (Lowe, 1982; Shultz, 1984). Considerando que estos depósitos se encuentran en una zona de baja pendiente, en donde el cauce principal desaparece, la abrupta pérdida del contenido de agua sería el principal disparador en la depositación de esta litofacies.

\section{Canales secundarios de carga areno-limosa (CHd-LS)}

Son canales poco definidos, de lecho plano, que varían entre 20 y $40 \mathrm{~m}$ de ancho, algunos conectados con los canales principales, y otros simplemente aparecen inmersos en la llanura de inundación, entre los lóbulos terminales (Figs. 5 y 12). Estos canales están formados en general por materiales finos arcillolimosos y arenosos (Sh, $\mathrm{S}(\mathrm{G}) \mathrm{h}$ y Fl; Tabla 1). Los canales secundarios se caracterizan por presentar una 
mayor concentración de la vegetación, alcanzando valores de SAVI de hasta 0,32. Muchos de estos canales se pierden por infiltración, y solo algunos alimentan en forma superficial a la salina.

Interpretación: son formados por el escurrimiento de agua superficial durante tormentas y/o grandes crecidas del río en zonas localmente deprimidas, tienden a distribuir el agua dentro de la llanura, y a diferencia de los canales secundarios de la zona 2 no vuelven al canal principal (Makaske, 2001; Nichols y Fisher, 2007). Los mismos depositan arenas en condiciones de alto régimen de flujo-flujo crítico (Miall, 1977; Tunbridge, 1981; Miall, 1996).

\section{Dunas menores o protodunas (Dm)}

Son acumulaciones arenosas de 0,50 a $2 \mathrm{~m}$ de altura, en montículos aislados o en cordones alineados, aunque su diseño en planta está alterado por presentar abundante vegetación, lo que dificulta su clasificación (Figs. 5 y 12f). La orientación de los vientos que las forman es S- SO siguiendo el patrón regional (Suvires, 1996; Tripaldi y Forman, 2007). Las litofacies que las componen son arenas finas laminadas con gradación inversa (Slg) y lateralmente facies finas y evaporíticas (Fl- Ev). La vegetación asociada presenta en general valores de SAVI de 0,32 a 0,62 , alcanzando valores de hasta 0,77 .

Interpretación: estos depósitos, de origen eólico, han sido interpretados como dunas de sombra (sand shadow o sand drift; Bagnold, 1954) o zibars de hasta $2 \mathrm{~m}$ que crecen verticalmente por la migración de óndulas eólicas (Limarino y Martínez, 1992; Tripaldi, 2002). Depósitos similares son descritos por Tripaldi y Limarino (2008) en el valle del río Guandacol.

\section{Charcas (P)}

Son acumulaciones de agua temporales que depositan sedimentos finos y sales, Fl-Ev. Los mismos poseen forma irregular y se encuentran distribuidas aisladamente en la porción distal de la zona 3 (Fig. 5). Estas charcas cubren una superficie de hasta $15 \mathrm{Ha}$ y en general se encuentran secas o ligeramente humedecidas en los sectores más profundos. La vegetación en los bordes es abundante, alcanzando un SAVI de hasta 0,32 y hacia el centro es prácticamente nula. En la superficie se observan grandes grietas de desecación (decimétricas) vinculadas a láminas de sales.

Interpretación: las charcas se producen por la intersección de la superficie topográfica con la napa freática, la cual se eleva durante la estación estival como consecuencia de lluvias locales y el agua traída por los cursos del SFD desde las sierras. Esta superficie permanece inundada temporalmente durante esta época y luego se seca con un periodo de decantación de la arcilla en suspensión, posterior precipitación de sales y generación de grandes grietas de desecación.

\section{Zona de transición}

La zona 4 se define entre las coordenadas $31^{\circ} 27^{\prime} 28,46^{\prime \prime} \mathrm{S}-67^{\circ} 8^{\prime} 33,80^{\prime \prime} \mathrm{O}$ y $31^{\circ} 26^{\prime} 27,68^{\prime \prime} \mathrm{S}$ y $67^{\circ} 5^{\prime} 34,76^{\prime \prime}$ O corresponde a una zona de transición demarcada entre la finalización de los depósitos del SFD del arroyo Papagayos y la parte central de la salina (Fig. 5). Los límites entre la zona 3 y la 4, estarían demarcados entre la zona de afloramiento de la napa freática y el sector dominado por la agradación vertical de finos y sales en la salina, al que se suma la intervención eólica. Esta zona está representada por una estrecha franja de unos $2 \mathrm{~km}$ de ancho, y una pendiente de $0,35 \%$ en donde domina la acumulación de sedimentos clásticos muy finos en la época de lluvias (verano) y sales en la época donde no llegan sedimentos clásticos transportados por el arroyo Papagayos y otras fuentes fluviales. Esta franja está surcada por canales secundarios sinuosos que desaguan en la salina. Las litofacies definidas en este sector son Shm, Flw, Fl y Ev formando los elementos arquitecturales descritos a continuación.

\section{Dunas (D)}

Son acumulaciones arenosas que se presentan en cuerpos de hasta $5 \mathrm{~m}$ de altura y forman cordones paralelos, perpendiculares al borde de la salina, (Figs. 5 y 13a). Estas acumulaciones están formadas por material muy fino tipo limo-arenoso cuya fuente es el material removilizado de la salina y de la porción distal del SFD. Su arreglo interno presenta arenas muy finas con laminación horizontal a veces difusa (Shm) 
en sets de hasta $1 \mathrm{~m}$ (Fig. 13b). En la parte superior aparecen óndulas de arena fina a muy fina de cresta levemente sinuosa, con longitudes de onda de hasta $0,25 \mathrm{~m}$ con gradación inversa (Sre). Presentan mucha vegetación con valores de SAVI de 0,32 a 0,47 y cuevas que han generado la obliteración de la estructura sedimentaria original.

Interpretación: las litofacies que integran este elemento arquitectural y su geometría, permiten definir estos depósitos como grandes dunas longitudinales con orientación SE-NO (Ross, 1983; Suvires, 1986; Tripaldi y Forman, 2007; Scherer y Goldberg, 2010). La intensa bioturbación que presenta el tope de estas dunas oblitera su morfología original y evidencia periodos de estabilización(Kocurek, 1981; 1988; Kocurek y Havholm, 1993; Armas y Sánchez, 2013). De acuerdo con su orientación y estructura sedimentaria estas dunas son similares a las dunas lineares descritas en la sección de Mascasín por Tripaldi y Forman (2007).

\section{Interduna húmeda (ID)}

Son depresiones paralelas ubicadas entre las dunas vegetadas. Las mismas son surcadas por canales sinuosos, monocanalizados, de poca profundidad que se disponen en forma paralela entre sí y diagonales respecto al borde de la salina. Presentan litofacies arenosas (Sh), cortinas de fango (Fl), grietas de desecación y láminas de sal (Ev, Fig. 13c y d). En la superficie de los canales secos se observan óndulas de arena fina a muy fina (Sre) de cresta sinuosa con bifurcación de crestas de escala centimétrica, gradación inversa y longitudes de onda de hasta $0,20 \mathrm{~m}$. En ellos se concentran la vigorosa y abundante vegetación que crece en el borde de la salina, alcanzando valores de SAVI de 0,32. Es común observar bioturbación generada por huellas de animales que se preservan en las costras salinas (Fig. 13c).

Interpretación: la morfología de estas depresiones, paralelas entre las dunas, así como su relleno sedimentario formado por depósitos de flujos en manto laminares y evaporitas permite interpretarlos como interdunas (Langford y Chan, 1989; Mountney, 2012; Armas y Sánchez, 2013). La presencia de canalización así como la alta concentración de vegetación permite clasificarla como una interduna húmeda (Armas y Sánchez, 2013).

\section{Lagunas de fangos salinos (SP)}

Son cuerpos de agua temporarios donde se acumulan limos y arcillas rojizas y oscuras $\left(\mathrm{Fl}_{\mathrm{w}}, \mathrm{Fl}\right)$, intercaladas con láminas de sales (Ev). En la superficie de las capas clásticas se preservan marcas de gotas de lluvia, huellas de animales y grietas de desecación (Figs. 5 y 13e). La disolución de las láminas de sales altera la estructura original de las fracciones clásticas generando un aspecto grumoso de la superficie y deformación de los bordes de las grietas de desecación (Fig. 13f). La vegetación es aislada y el índice SAVI es prácticamente nulo (menor a 0,028 ).

Interpretación: la sedimentación en estos cuerpos de agua someros se produce por la decantación de materiales finos. El viento genera oleaje que retrabaja estos sedimentos y genera las ondulas de oscilación (Arche, 2010). La desecación progresiva del área conduce a la formación de frecuentes grietas de desecación y la modificación de la fábrica original por la bioturbación de organismos tolerantes a la aridez y la salinidad (Arche, 2010). Las láminas de sales y costras salinas son generadas a través de la precipitación al ir alcanzándose progresivamente los productos de solubilidad (saturación) de las diferentes sales disueltas (Raup, 1970; Orti Cabo, 2010). En regiones semiáridas y áridas terrestres precipitan evaporitas debido a la fuerte insolación y alta evaporación, particularmente en las franjas latitudinales N y S comprendidas entre $\operatorname{los} 15^{\circ} \mathrm{y} \operatorname{los} 40^{\circ}$, donde frecuentemente la pluviosidad es inferior a 100-200 mm anuales (Orti Cabo, 2010). 